\title{
INVESTOR SENTIMENT AND BOND RISK PREMIA
}

\author{
Ricardo Laborda $\mathrm{a}^{\mathrm{a}^{*}}$, Jose Olmo ${ }^{\mathrm{b}}$ \\ ${ }^{a}$ Centro Universitario de la Defensa. Zaragoza (Spain) \\ ${ }^{\mathrm{b}}$ Economics Division, School of Social Sciences. University of Southampton
}

\begin{abstract}
This article studies the statistical significance of the set of market sentiment variables proposed by Baker and Wurgler (2006) to predict the risk premium on U.S. sovereign bonds. We show that these variables can be summarized in one single market sentiment factor similar in spirit to the single-return forecasting factor proposed by Cochrane and Piazzesi (2005). Our findings reveal that this factor has predictive power beyond that contained in the yield curve and benchmark macroeconomic factors. The predictive power of this variable is time-varying, exhibiting more relevance during recession periods.
\end{abstract}

Keywords: Bond risk premia; Forward prices; Investor sentiment; Bootstrap standard errors; Wald tests.

JEL Classification: E4; G11; G12.

*Corresponding Author: Ricardo Laborda. E-mail: rlaborda@unizar.es. Phone: +349767076. Centro Universitario de la Defensa de Zaragoza. Academia General Militar. Ctra. Huesca s/n. 50090. Zaragoza. Spain. Ricardo Laborda acknowledges financial support from CreaValor Research Group financed by DGA-FSE and Jose Olmo from the Spanish Government through project MICINN ECO2011-22650. 


\section{Introduction}

The expectations theory of the term structure of interest rates states that long yields are the average of future expected short yields. This theory implies that the expected excess returns on bonds should not be forecastable. Despite prominent efforts to provide empirical support to this theory its failure is largely documented in many studies. Thus, Fama and Bliss (1987) and Campbell and Shiller (1991) using the forward-spot rate differential and the slope of the yield curve as predictor variables report evidence on the existence of time-varying risk premiums in US bond markets implying that excess returns have a predictable component. Cochrane and Piazzesi (2005) find further evidence on predictability using a tent-shaped linear combination of five forward rates, which succeed at predicting the one-year excess return of the $n$-year bond $(n=2 \ldots 5)$ with an $\mathrm{R}^{2}$ higher than $35 \%$ in most cases. These findings imply that conditional expectations of excess returns on US government bonds across maturities can be expressed in terms of forward rates observed at time t. Cochrane and Piazzesi (2005) introduce this "single-return factor" that appears to be countercyclical and cannot be entirely explained by the level, slope and curvature of the yield curve. Dahlquist and Hasseltoft (2011) extend Cochrane and Piazzesi (2005) results to international bond markets by allowing for the existence of a local factor that is positively associated with the slope of local yield curves and a global factor correlated with the US bond risk premia, and that have significant forecasting power for international bond returns.

Recent literature has documented the existence of factors that link the countercyclical behavior of bond risk premia with expected excess returns on US government bonds at the highest (lowest) levels during recession (expansion) periods, to variables not directly extracted from the yield curve. Ludvigson and $\mathrm{Ng}$ (2009) find that "real" and "inflation" factors, constructed from dynamic factor analysis to 132 monthly economic series, have important forecasting power for future excess returns on US government bonds above and beyond the predictive power contained in forward rates and yield spreads. The macro factors proposed by these authors combined with the Cochrane and Piazzesi factor reach an $\mathrm{R}^{2}$ higher than $40 \%$ across maturities and also display a countercyclical behaviour, implying that bond risk premia is tied to a compensation required by the investor for bearing risks related to recessions. Cooper and Priestly (2009) find that the output gap also has predictive power for excess bond returns beyond that of the term structure. Duffie (2011) documents the presence of a 
factor that appears to be related to short-run fluctuations in economic activity. This factor has an almost imperceptible effect on the cross section of yields but has a strong forecasting power for future short-term interest rates and excess bond returns.

Bond prices are also affected by subjective investors' beliefs on the state of the economy. It is surprising however the absence of empirical studies assessing the impact of investor sentiment for explaining and predicting bond risk premia. This is not the case for asset markets, thus, Baker and Wurgler (2006) show that investor sentiment disproportionately affects securities whose valuations are highly subjective and are difficult to arbitrage away. They find that when beginning-of-period proxies for investor sentiment are low, subsequent returns are relatively high on small stocks, young stocks, high volatility stocks, unprofitable stocks, non-dividend-paying stocks, extreme-growth stocks and distressed stocks, suggesting that such stocks are relatively underpriced in low-sentiment states. When sentiment is high, on the other hand, the patterns largely reverse, suggesting that these categories of stocks are relatively overpriced in this state. Baker and Wurgler (2006) define an investor sentiment index as the first principal component of the correlation matrix of six variables underlying proxies for sentiment. These proxies, orthogonalized to several macroeconomic variables, are: 1) the closedend fund discount, which is the average difference between the net asset value of closed-end stock fund shares and their market prices. 2) NYSE share turnover, based on the ratio of reported share volume to average shares listed from the NYSE Fact Book. 3) the number of IPOs. 4) the average first-day returns. 5) the share of equity issues in total equity and debt issues, which is a measure of financing activity and 6) the dividend premium.

The aim of this paper is to investigate into the relationship between market sentiment variables and the existence of a risk premium in bond markets. More specifically, our interest is in assessing the statistical predictive power of investor sentiment for describing bond risk premia at different maturities. To do this, we extend the methodology proposed by Cochrane and Piazzesi (2005) and Ludvigson and Ng (2009) by incorporating a sentiment factor constructed from the set of variables introduced in Baker and Wurgler (2006) reflecting market sentiment. Our main contribution is to document empirically a positive relationship between investor sentiment variables and expected excess bond returns that is beyond and above the information contained in the term structure of bonds and macroeconomic factors. The in-sample regressions show an $\mathrm{R}^{2}$ that reaches nearly $50 \%$ for some maturities and 
sample periods giving support to the existence of an investor sentiment factor in bond risk premia especially relevant for shorter maturities. The out-of-sample evidence also shows the outperformance of the augmented model that includes investor sentiment variables compared to the restricted model especially after periods of very high sentiment. We also find empirical evidence on the relationship between short and long maturity bonds conditional on investor sentiment, in particular we observe that high investor sentiment, which is mean reverting, favours the excess returns on long maturity bonds over the one-year bond.

As a byproduct of our analysis, we formalize the existence of a sentiment forecasting factor that adds to the single-return forecasting factor based on the term structure of interest rates and originally proposed in Cochrane and Piazzesi (2005) and the macroeconomic factor introduced by Ludvigson and $\mathrm{Ng}$ (2009). We do this by implementing statistical tests to assess the differences in explanatory power between unrestricted and restricted versions of regression models exploring the relationship between the sets of variables describing macroeconomic fundamentals and market sentiment, respectively, and the excess return on US government bonds with maturities between 2 and 5 years. Our results for the period August 1965 to December 2007 show overwhelming statistical evidence on the existence of single factors that summarize macroeconomic fundamentals and market sentiment in a similar way as the single return-forecasting factor does. We finally carry out several robustness exercises to assess the reliability of our results. In particular, we repeat the analysis using an alternative database of US yields constructed by Gurkaynack, Sack and Wright (2006) that contains maturities longer than five years. The results of this analysis support our empirical findings.

This article fills the absence of academic work on the effect of investor sentiment on government bond pricing. A notable exception to this gap is Baker and Wurgler (2012). These authors analyze the relationship between sentiment and the comovement between government bonds and bond-like stocks, characterized as being long mature, low volatility, profitable, from dividend-paying firms and that are neither high growth nor distressed. Using monthly excess portfolio returns, these authors find that when the investor sentiment index is high and subsequent returns on bond-like stocks are expected to outperform speculative stocks, bond returns are also expected to be positive. Baker and Wurgler (2012) also argue that an explanation for the predictability patterns they document should jointly be based on shocks to real cash 
flows, shocks to discount rates and time-varying investor sentiment that is linked to market risk aversion. Nayak (2010) also explores the impact of investor sentiment on corporate bond yield spreads, finding that corporate bonds appear underpriced (with high yields and spreads) when beginning-of-period sentiment is low, and overpriced (with low yields and spreads) when beginning-of-period sentiment is high. Under (over) priced bonds, especially the low rated, in low (high) investor sentiment periods have subsequent lower (higher) yield spreads.

Investor sentiment appears to be linked to biases in the projections of future cash flows and especially to the assessment of the outlook of risk, which is a key ingredient of the relative demand of stocks vs. bonds. According to the sentiment index proposed by Baker and Wurgler (2006), high investor sentiment periods are associated to high equity issuances in an overpriced stock market, increasing number of IPOs with high average first day returns, high NYSE share turnover and decreasing closed-end funds discount. These market characteristics determine bull stock markets and investors' high risk-appetite. These periods are usually characterized by increasing interest rates and the presence of less risk averse investors willing to demand highly risky assets vs. safe assets, as government bonds. However, when the optimism reverts to the historical mean, the market proceeds to correct absolute and relative mispricing, and especially in distressed times the safety offered by US sovereign debt triggers the flight to quality form the riskiest assets (stocks and high yield bonds) to the safest assets. High investor sentiment periods anticipate high ex-post bond excess returns as a consequence of a posterior inward movement of the forward interest rate curve, reflecting an increasing risk aversion. Consumption based models can explain time varying risk aversion using a habit specification model. Campbell and Cochrane (1999) show that when consumption is high relative to some "trend" or the recent past, investors' risk aversion and the corresponding risk premia increase, negatively affecting risky asset prices. The model developed by Campbell and Cochrane (1999) displays a countercyclical behaviour of the Sharpe ratio linked to the behaviour of the business cycle that can be reconciled with the behaviour of interest rates, using a precautionary saving explanation. When consumption is low relative to the habit, investors are not willing to assume risks and save more in order to build up assets against the event that tomorrow might be even worse. This precautionary desire to save drives down interest rates. These results suggest that the main channel for the transmission of market sentiment, which is formed using variables from the equity market, into bond returns is through nominal interest 
rates. Indeed, the stock can be viewed as a long-term bond plus cash flow risk, so any variable that forecasts stock returns can also potentially forecast bond returns and vice versa. We hypothesize that low (high) investor sentiment periods are related to exceptionally high (low) investor risk aversion periods and decreasing (increasing) interest rates, which induce the reversion of absolute and relative mispricing.

The article is structured as follows. Section 2 lays out the econometric framework and discusses the different methodologies to explain the risk premia on bond returns. In Section 3 we formalize the existence of a macroeconomic and a sentiment forecasting factor that add to the single-return forecasting factor based on the term structure of annual implicit forward rates. To do this we implement the statistical tests discussed in Cochrane and Piazzesi (2005). Section 4 presents the in-sample results of the one-year-ahead predictive regressions from the different econometric specifications. This section also discusses different robustness measures to provide empirical support to the findings. These robustness measures include an out-of-sample rolling window, which also evaluates the economic relevance of including the investor sentiment factor to explain bond risk premia through a very simple asset allocation process, and an alternative choice of database containing US yields with maturity longer than five years. Section 5 concludes.

\section{Econometric framework: Bond returns}

This section discusses the methodology proposed by Cochrane and Piazzesi (2005) and Ludvigson and $\mathrm{Ng}$ (2009) for constructing their single-return forecasting factors. We accommodate this two-stage regression procedure to define a new market sentiment factor given by an optimal linear combination of variables related to the investor sentiment index discussed in Baker and Wurgler (2006).

Let $p_{t}^{(n)}$ be the $\log$ price of an n-year zero-coupon bond at time $\mathrm{t}$. We use parentheses to distinguish maturity from exponentiation in the superscript. The log yield is

$$
y_{t}^{(n)}=-(1 / \mathrm{n}) p_{t}^{(n)}
$$

Under no-arbitrage conditions, the continuously compounded forward rates satisfy that

$$
f_{t}^{n-1 \rightarrow n}=p_{t}^{(n-1)}-p_{t}^{(n)}
$$


We consider the strategy of buying an n-year zero coupon bond at time $t$ and selling it as an $n-1$ year bond at time $t+1$. The return on this strategy after one period is

$$
r_{t+1}^{(n)}=p_{t+1}^{(n-1)}-p_{t}^{(n)}
$$

and the excess return obtained from substracting the yield on the one-year bond is

$$
r x_{t+1}^{(n)}=\mathrm{r}_{t+1}^{(n)}-y_{t}^{(1)}=p_{t+1}^{(n-1)}-p_{t}^{(n)}-y_{t}^{(1)}
$$

Further, after some algebra, the bond price can be expressed as:

$$
p_{t}^{(n)}=-\sum_{j=0}^{\mathrm{n}-1} \mathrm{f}_{t}^{j \rightarrow j+1}
$$

with $f_{t}^{0 \rightarrow 1}=y_{t}^{(1)}$, that can be used to substitute prices away from (3). The excess return can be written as

$$
r x_{t+1}^{(n)}=\sum_{j=1}^{\mathrm{n}-1} \mathrm{f}_{t}^{j \rightarrow j+1}-\sum_{j=1}^{\mathrm{n}-1} \mathrm{f}_{t+1}^{j-1 \rightarrow j}
$$

Excess returns depend on the set of present forward rates and the corresponding set of next year forward rates with maturities decreased by one year. Assuming rational expectations, the deviations from the expectations hypothesis of the term structure should be explained by the presence of a bond risk premia defined as

$$
E_{t}\left(r X_{t+1}^{(n)}\right)=\sum_{j=1}^{\mathrm{n}-1} \mathrm{f}_{t}^{j \rightarrow j+1}-E_{t}\left(\sum_{j=1}^{\mathrm{n}-1} \mathrm{f}_{t+1}^{j-1 \rightarrow j}\right)
$$

where $E_{t}()=.E\left(. \mid \Omega_{t}\right)$ denotes the mathematical expectation conditional on $\Omega_{t}$, the sigma-algebra containing the set of all available information at time t. We use overbars to denote averages across maturities. Thus,

$$
\overline{r x}_{t+1}=(1 / 4) \sum_{n=2}^{5} r x_{t+1}^{(n)}
$$

denotes the average excess return on an equally-weighted portfolio of bonds with maturities between two and five years.

Cochrane and Piazzesi (2005) study the predictive power of the term structure of interest rates for explaining the one year excess returns in (6). These authors find that a linear combination of five forward spreads explains between $30 \%$ and $35 \%$ of the variation in next year's excess returns on bonds with maturities ranging from two to five years. The regression specification proposed by these authors is a two-step procedure. First, they estimate a regression of the average (across maturity) excess return on all forward rates, 


$$
\overline{r x}_{t+1}=\lambda_{0}+\lambda_{1} y_{t}^{(1)}+\lambda_{2} f_{t}^{1 \rightarrow 2}+\lambda_{3} f_{t}^{2 \rightarrow 3}+\lambda_{4} f_{t}^{3 \rightarrow 4}+\lambda_{5} f_{t}^{4 \rightarrow 5}+u_{t+1}
$$

where $u_{t}$ is the error term of the regression. Second, they use the fitted values from this regression, denoted hereafter as $\mathrm{CP}_{t}$, as an excess bond return predictor for all maturities:

$$
r x_{t+1}^{(n)}=b_{n} C P_{t}+\varepsilon_{t+1}^{(n)}=b_{n}\left(\lambda_{0}+\lambda_{1} y_{t}^{(1)}+\lambda_{2} f_{t}^{1 \rightarrow 2}+\lambda_{3} f_{t}^{2 \rightarrow 3}+\lambda_{4} f_{t}^{3 \rightarrow 4}+\lambda_{5} f_{t}^{4 \rightarrow 5}\right)+\varepsilon_{t+1}^{(n)}
$$

Cochrane and Piazzesi (2005) denominate $\mathrm{CP}_{\mathrm{t}}$ as the "single return-forecasting factor" and observe a tent-shaped form for the regression parameters in (9). These authors formalize the existence of this factor by deploying a battery of statistical tests assessing the predictive power of this factor compared to that of the unrestricted regression

$$
r x_{t+1}^{(n)}=\beta_{0}+\beta_{1} y_{t}^{(1)}+\beta_{2} f_{t}^{1 \rightarrow 2}+\beta_{3} f_{t}^{2 \rightarrow 3}+\beta_{4} f_{t}^{3 \rightarrow 4}+\beta_{5} f_{t}^{4 \rightarrow 5}+\varepsilon_{t+1}^{(n)}
$$

The restricted model is equivalent to setting the restriction $\beta=b_{n} \lambda$.

We also consider the role of macroeconomic variables with statistical power to explain variation on the bond risk premia. This is done by running predictive regressions of bond excess returns on the Ludvigson and $\mathrm{Ng}$ (2009) six-factor model that minimizes the BIC criterion for the forecasting regressions of excess bond returns across different specifications. This vector of regressors is a subset of the set of dynamic factors found in Ludvigson and $\mathrm{Ng}$ (2009) that summarize the informational content on 132 monthly economic series. These authors propose two different but related specifications of the risk premium and use the same two-stage procedure as in Cochrane and Piazzesi (2005) to construct a macroeconomic factor analogous to the single-return forecasting factor. The first regression model takes this form:

$$
\overline{r X}_{t+1}=\theta_{0}+\theta_{1} F_{1 t}+\theta_{2} F_{1 t}^{3}+\theta_{3} F_{2 t}+\theta_{4} F_{3 t}+\theta_{5} F_{4 t}+\theta_{6} F_{8 t}+v_{t+1}
$$

with $v_{t+1}$ the error term of the regression. These authors interpret the first factor, $F_{1 t}$, as a real factor related to employment, production, capacity utilization and new manufacturing orders; the second factor, $F_{2 t}$, is linked to several interest rate spreads; the third and fourth factors, $F_{3 t}$ and $F_{4 t}$, are inflation factors related to nominal interest rates and the eighth factor, $F_{8 t}$, is a stock market factor. The second specification of the predictive regression model proposed by these authors also considers the CP factor. In this specification the factor $F_{2 t}$ is highly correlated with interest rate spreads and its 
information about the bond risk premia is subsumed in the $\mathrm{CP}$ factor, being dropped from the regression model that becomes

$$
r x_{t+1}^{(n)}=b_{n, C P} C P_{t}+b_{n, L N} L N_{t}+\varepsilon_{t+1}^{(n)}
$$

with $\mathrm{LN}_{\mathrm{t}}$ defined as the fitted values from (12) but with the variable $\mathrm{F}_{2 \mathrm{t}}$ dropped from the regression model.

In this paper, we augment these models by including variables related to the investor sentiment index $\left(\mathrm{S}_{t}^{\perp}\right)$ constructed in Baker and Wurgler (2006) and discussed above. Following the strategy developed by Cochrane and Piazzesi (2005) and Ludvigson and $\mathrm{Ng}$ (2009) we construct a synthetic variable, $\mathrm{BW}_{\mathrm{t}}$ hereafter, that defines a new factor reflecting investor sentiment. This predictive factor is defined as the projection of $\overline{r x}_{t+1}$ on $\mathrm{S}_{t}^{\perp}, \mathrm{S}_{t}^{\perp 2}$ and $\Delta \mathrm{S}_{t}^{\perp}$, with $\mathrm{S}_{t}^{\perp}$ a sentiment index that is orthogonal to a sample of macroeconomic factors selected by Baker and Wurgler (2006), $\mathrm{S}_{t}^{\perp 2}$ is the square of the sentiment variable and reflects the magnitude of the underlying sentiment and $\Delta \mathrm{S}_{t}^{\perp}$ that measures the variation in sentiment. More specifically, the sentiment factor is obtained from the following regression:

$$
\overline{r x}_{t+1}=\phi_{0}+\phi_{1} \mathrm{~S}_{t}^{\perp}+\phi_{2} \mathrm{~S}_{t}^{\perp 2}+\phi_{3} \Delta \mathrm{S}_{t}^{\perp}+\tau_{t+1}
$$

with $\tau_{t+1}$ the error term of this regression. The sentiment factor $\mathrm{BW}_{\mathrm{t}}=\widehat{\mathrm{rX}_{t+1}}$ allows us to extend the model in Ludvigson and $\mathrm{Ng}$ by incorporating investor sentiment for predicting the risk premium on bond returns. The proposed model is

$$
r x_{t+1}^{(n)}=b_{n, C P} C P_{t}+b_{n, L N} L N_{t}+b_{n, B W} B W_{t}+\xi_{t+1}^{(n)}
$$

with $\xi_{t+1}^{(n)}$ the error term of the regression.

\section{Factors for predicting bond risk premia}

This section describes the data used in our empirical analysis of the risk premium on US sovereign bond returns and assesses the statistical validity of single factor models proxying information on sovereign bond markets, macroeconomic conditions and market sentiment rather than unrestricted versions assigning different coefficients to each of the regressors in a long multivariate predictive regression model difficult to interpret in terms of the above factors. 


\subsection{Data}

We use the Fama-Bliss dataset available from the Center for Research in Securities Prices (CRSP) and contains observations on one- through five-year zero-coupon US Treasury bond prices covering the period between August 1965 and December 2007. We construct data on excess bond returns, yields, and forward rates, as described above. Annual returns are constructed by continuously compounding monthly return observations. We use the estimated macro factors available at Sydney Ludvigson's web page (http://www.econ.nyu.edu/user/Ludvigsons/) to estimate the $\mathrm{LN}_{\mathrm{t}}$ factor and the index $\mathrm{S}_{t}^{\perp}$ available at Jeffrey Wurgler' page (http://pages.stern.nyu.edu/ jwurgler/).

[Insert Figures 1 and 2 about here]

Figure 1 plots the sentiment index that lines up with the anecdotal accounts of bubbles and crashes over the period 1965 and 2007 discussed in Baker and Wurgler (2006), along with shaded NBER recessions dates. Table 1 presents the correlation matrix between the excess bond returns, $x_{t+1}^{(n)}(\mathrm{n}=2, \ldots, 5)$ and the explanatory variables used in regression (15). To obtain some insight into the correlation between the excess bond returns and the sentiment factor we have broken down the underlying sentiment variables. All the explanatory factors are twelve-month lagged. The Cochrane and Piazzesi factor, $\mathrm{CP}_{\mathrm{t}}$, and the Ludvigson and $\mathrm{Ng}$ (2009) macro factor, $\mathrm{LN}_{\mathrm{t}}$, are positively correlated to future excess bond returns with levels larger than $40 \% . \mathrm{S}_{t}^{\perp}$ and $\mathrm{S}_{t}^{\perp 2}$ are also positively correlated to future excess bond returns and $\Delta \mathrm{S}_{t}^{\perp}$ is strongly negatively correlated to future excess bond returns. Interestingly, investor sentiment variables are almost uncorrelated, and $\mathrm{S}_{t}^{\perp}$ and $\Delta \mathrm{S}_{t}^{\perp}$ are positively and negatively related to the $\mathrm{CP}_{\mathrm{t}}$ and $\mathrm{LN}_{\mathrm{t}}$ factors, respectively. The variable $\mathrm{S}_{t}^{\perp 2}$ is almost uncorrelated with the $\mathrm{CP}_{\mathrm{t}}$ and $\mathrm{LN}_{\mathrm{t}}$ factors. As expected, the investor sentiment index is positively correlated with the interest rate variables, $y_{t}^{(1)}, f_{t}^{1 \rightarrow 2}, f_{t}^{2 \rightarrow 3}, f_{t}^{3 \rightarrow 4}$ and $f_{t}^{4 \rightarrow 5}$, reaching values about 0.30 in the considered sample period. Figure 2 shows that the 10 year moving average correlation between the investor sentiment index and the US Fed rate is positive, increasing especially in high investor sentiment periods. Periods of high investor sentiment seem to be associated with lowering investor risk aversion and a higher desire to borrow against the future, that drives up interest rates. Our main focus is on the 
"unusually" high investor sentiment periods that could convey valuable information about future US excess government bond returns beyond the information embedded in the yield curve and macro factors.

[Insert Table 1 about here]

\subsection{Testing the single return-forecasting factors}

One of the main contributions of Cochrane and Piazzesi (2005) is to show that the same set of regressors explains the variation on excess bond returns for all maturities. These authors also discuss statistical tests to disentangle the efficiency loss incurred by using a single factor instead of the full set of regressors. Table 2 reports the estimates of both unrestricted and restricted models corresponding to the $\mathrm{CP}$ factor for the period August 1965 to December 2007. The results are very similar to those found by Cochrane and Piazzesi (2005) for a sample ending on 2003. To formalize these findings Cochrane and Piazzesi (2005, p. 156) deploy two statistical tests: a $J_{T}$ test to assess whether the moment conditions imposed for the estimation of the unrestricted model are violated by the restricted version of the model and a Wald test of the joint parameter restrictions implied by the restricted model. The results of these tests validate the use of the restricted model defining the $\mathrm{CP}$ factor. The p-values of the asymptotic and bootstrap versions of the tests can be found as an online appendix.

We follow the methodology described by these authors and show that the single sentiment factor estimated from (14) is also a reliable representation of the set of variables reflecting investor sentiment. Table 3 reports the estimates of the unrestricted and restricted versions of the model that only considers investor sentiment. The results suggest a positive and linear effect of the sentiment variable that increases with maturity. The variable reflecting differences in market sentiment has a negative effect on the excess returns suggesting that a positive one-year investor sentiment momentum implies a drop in bond risk premia. The $\mathrm{R}^{2}$ coefficients are between 0.144 and 0.084 and decrease with the time to maturity. The restricted model reveals that there is an overall positive effect between market sentiment and bond risk premia that increases with time to maturity. Both tables present the Hansen and Hodrick (1983) asymptotic standard errors and the bootstrap standard errors derived from assuming a VAR(12) model for 
the one-year yield, see Cochrane and Piazzesi (2005, Section C.2 of online Appendix) available at http://www.aeaweb.org/aer/contents/appendices/mar05 app_cochrane.pdf. The reported differences in standard error estimates between OLS and GMM and bootstrap techniques suggest that standard estimation methods not considering the presence of overlapping data can be inadequate for modelling annual excess returns when using monthly frequency data. These authors also discuss Newey and West (1987) asymptotic standard errors in order to account nonparametrically for the presence of heteroscedasticity and serial correlation in the errors. For sake of space the results for the Newey-West case with 18 lags are only reported for the Wald and $\mathrm{J}$ tests. For the rest of regression analyses these standard errors are not reported although are available from the authors upon request.

Table 4 presents the test statistics and p-values for the $\mathrm{J}_{\mathrm{T}}$ test and Wald tests discussed above. Following Cochrane and Piazzesi (2005), this is done for different lags of the regressor variables, with $i=0$ denoting the regressors one-year lagged, $i=1$ denoting the regressors 13 months lagged and so on. The results reveal some discrepancies between the asymptotic and bootstrap tests, and also between the test statistics obtained using the correction by Newey-West and the no overlapping method. Overall, both types of tests in Table 4 reveal that the loss in predictive power is not statistically significant and validate the use of the factor BW to proxy market sentiment.

\section{[Insert Tables 2, 3 and 4 about here]}

Figure 3 shows the pattern of the regression coefficients. The top panel presents unrestricted estimates of the model parameters for each maturity. The bottom panel presents restricted parameters obtained from the two-step procedure. These charts also provide graphical evidence on the similarity between the unrestricted and restricted regression models. The main sentiment variables with forecasting power are $\mathrm{S}_{t}^{\perp}$ (indexed by 1 in the $\mathrm{x}$ axis) and $\Delta \mathrm{S}_{t}^{\perp}$ (indexed by 3 in the $\mathrm{x}$ axis).

[Insert Table 5 and Figure 3 about here]

For completeness, Table 5 presents the estimates of the unrestricted and restricted versions of the predicted regression model proposed by Ludvigson and $\mathrm{Ng}$ 
(2009). These results illustrate the importance of considering $\mathrm{LN}_{\mathrm{t}}$ for predicting the risk premium on bond returns. Interestingly, all factors are statistically significant except $\mathrm{F}_{3}$, an inflation factor related to interest rates. The $\mathrm{R}^{2}$ oscillates between 0.22 for bonds with maturity in two years and 0.141 for bonds with five year maturity.

\section{Predictive regressions for bond risk premia}

This section analyses the bond risk premia predictive performance of the different sets of factors: forward interest rates, macroeconomic variables and investor sentiment summarized in three single return-forecasting factors as discussed above. The dynamics of these factors and the bond excess returns, shown in Figure 4, reveal strong comovements between the factors during some periods but absence of correlation during other market episodes. The sentiment index factor exhibits the lowest variability within the factors and the $\mathrm{CP}$ factor the highest variability.

[Insert Figure 4 about here]

\subsection{In-sample predictive performance}

Our aim in this section is to empirically assess the gains of considering market sentiment in the predictive regression model. Tables 6 and 7 present the results from insample forecasting regressions. In particular, Table 6 presents results from in-sample forecasting regressions of the general form (15) for two-, three-, four-, and five- year bond excess returns using the whole sample. In order to assess the relative importance of each factor over different periods, in-sample forecasting regressions estimates are reported in Table 7 for different subsamples. The choice of these evaluation samples is taken from Cochrane and Piazzesi (2005, Appendix, Table A.8) and coincides with periods marked by different inflation dynamics over several decades ${ }^{1}$.The results highlight the predictive role of each of the factors over the different periods under study.

The CP factor is strongly statistically significant and forecasts expected excess bond returns across different maturities with an adjusted $\mathrm{R}^{2}$ larger than $30 \%$. The loadings $\phi_{C P}$ of expected excess bond returns on the $\mathrm{CP}_{\mathrm{t}}$ factor increase smoothly with

\footnotetext{
${ }^{1}$ Unreported Chow tests, see Chow (1960), show overwhelming statistical evidence of the existence of two regimes across subsamples. The p-values are zero in most cases and for both the unrestricted and restricted models.
} 
maturity. The contribution of the $\mathrm{LN}$ factor to the predictive model adds an $\mathrm{R}^{2}$ of about $10 \%$, the $\mathrm{LN}$ factor is more relevant for shorter maturities. The coefficient corresponding to the Ludvigson and $\mathrm{Ng}$ factor is highly significant across maturities and increases with maturity. Tables 6 and 7 also report the estimates of the regression model for the average excess return over the four maturities. For these cases we also report the marginal contributions of each factor to the $\mathrm{R}^{2}$ statistic. For the full sample, in Table 6 , we observe an increase of $8 \%$ in explanatory power between the basic model and the version incorporating the macroeconomic factor. The analysis for different subsamples in Table 7 reveals significant differences in the importance of LN over the evaluation period. This is particularly notorious for the highly inflationary period January 1970 December 1979.

\section{[Insert Tables 6 and 7 about here]}

The above empirical analysis provides mixed results on the empirical relevance of the market sentiment variables. Interestingly, the gain in predictive power depends very much on the evaluation period. The analysis of the full sample reveals marginal gains obtained from including the sentiment factor. This can be also observed from the marginal contribution of the variables to the $\mathrm{R}^{2}$ of the regression on the average excess return over maturities. On the other hand, for the period August 1965 - December 1969 the gain in $\mathrm{R}^{2}$ is very significant, achieving for example an increase of $14 \%$ for the average excess return. During this period, coinciding with a hump in the market sentiment index as shown in Figure 1, this factor has a negative and very significant effect on the bond risk premia that is observed across maturities. Similar findings are noted over the periods January 1970 - December 1979 and January 2000 - December 2007. The explanatory power of the extended model is remarkable over the last period. The $\mathrm{R}^{2}$ achieves values higher than $40 \%$ for some maturities. In contrast to the 1970 decade the sentiment factor has a positive effect on the risk premia. For other periods where the market sentiment index does not fluctuate much, see Figure 1, the influence of this factor is not relevant. During these periods bond risk premia is better explained by financial market factors and macroeconomic fundamentals. The analysis for the rest of subsamples studied in Cochrane and Piazzesi (2005) is also found in Table 7. 


\subsection{Robustness checks}

This section provides some robustness checks to assess the existence of an investor sentiment factor with power to predict excess bond returns on US government bonds.

The out-of-sample forecasting performance of the regression models is very important to test the parsimony of the different regression specifications. To assess the relative out-of-sample predictability we carry out two exercises. First, we compute the mean square prediction error of the unrestricted and restricted models, denoted $\mathrm{MSPE}_{\mathrm{u}}$ and $\mathrm{MSPE}_{\mathrm{r}}$, respectively; and second, we test the statistical significance of these differences by implementing the Diebold and Mariano (1995) predictive ability test. This out-of-sample test is useful to assess the relative merit of two or more forecast alternatives by comparing the predictive ability of competing forecasts, given a general loss function, in our case we use the MSPE. The null hypothesis corresponds to equal predictive ability and rejection of the null corresponds to the superior predictive ability of one method over the other. In our case, rejection of the null hypothesis is interpreted as a better out-of-sample performance of the extended model that considers market sentiment against the reduced model only considering $\mathrm{CP}$ and $\mathrm{LN}$ factors.

To evaluate the out-of-sample performance of the models, we consider rolling regressions of 120 months estimated using the large-sample Hansen and Hodrick standard errors and the bootstrap counterparts, and covering different subperiods of the full evaluation sample. The initial estimation period spans the period August 1965 to December 1979 and considers data on bond excess returns over January 1980 to December 1989 as the out-of-sample period for model evaluation. The second period is constructed from moving forward all the relevant data ten years ahead. Thus, the insample estimation period covers August 1975 to December 1989 and the out-of-sample covers January 1990 to December 1999. The last period is defined by the interval August 1985 to December 1999 and considers the remaining eight years of data for outof-sample evaluation.

The values of $\mathrm{MSPE}_{\mathrm{r}}$ and $\mathrm{MSPE}_{\mathrm{u}}$ in Table 8 shed interesting findings. The first subsample uses the inflationary period August 1965 - December 1979 for estimating the coefficients of the predictive regression model. The MSPE is slightly larger for the unrestricted model than for the restricted version. Although the difference is small in relative terms it is statistically significant for the excess return on bonds with maturities between three and five years. The market sentiment factor overreacts to the inflationary 
period impeding a good performance of the model out of sample compared to the restricted model. The magnitude of the forecasting error for this period is also larger than for the other two subsamples. In contrast, for the second subsample the results are reversed; the MSPE is smaller for the unrestricted model and the magnitude of the forecasting error is also smaller during this period. During this period, the regression model extended with the market sentiment factor outperforms the simple model given by the $\mathrm{CP}$ and LN factors. The unrestricted model also outperforms the restricted version in terms of MSPE during the last subsample. However, the difference in the magnitude of the loss function between models is not sufficiently large to be able to reject the null hypothesis of superior predictive ability.

[Insert Table 8 about here]

We also evaluate the out-of-sample performance of the econometric models through an analysis of their economic importance using a very simple asset allocation process that strengthens the statistical results provided by the Diebold and Mariano test. Following Cochrane and Piazzesi (2005), we calculate the cumulative profits or "trading rule profits" for both the unrestricted and restricted model corresponding to the n-year bonds with $n=2,3,4,5$. The trading rule uses the forecast $E_{t}\left(r x_{t+1}^{(n)}\right)$ to recommend the size of a position which is subject to the ex-post return $r x_{t+1}^{(n)}$. The cumulative profits of the trading rule strategies, in Figures 5 to 8 , illustrate the superior performance of the unrestricted model in the second and third subsamples considered above, especially for the three-, four- and five- year bonds.

\section{[Insert Figures 5 to 8 about here]}

The last robustness exercise consists on assessing whether these findings are also supported for longer maturities. To do this we use an alternative database of US yields constructed by Gurkaynack, Sack and Wright (2006) that contains maturities up to thirty years at daily frequencies. The counterparts of Tables 3 and 6 are reported in Tables 9 and 10. The analysis for subsamples is reported as an online appendix. The results are in line with our previous findings. The parameter estimates corresponding to each factor are increasing with respect to the time to maturity of the bond except the effect of 
$\Delta \mathrm{S}_{t}^{\perp}$ in the unrestricted model that decreases with maturity. The sentiment index BW evaluated over the full sample period, covering the period August 1972 to December 2007, see Tables 9 and 10, is more relevant for shorter maturities. The coefficient of determination is rather stable across maturities. Nevertheless, as shown in Section 4.1 the sentiment index gains relevance in periods of high sentiment, especially if it is not highly correlated with the $\mathrm{CP}$ factor. Thus, the analysis of BW over subsamples confirms that the statistical significance of market sentiment is cyclical, being particularly relevant for periods characterized by high inflation dynamics as the decade of 1970. Market sentiment is also highly significant during the last period analyzed spanning from 2000 to 2007, where the forecasting power of the CP factor diminishes. This period corresponding to the great moderation is characterized by low inflation, low nominal interest rates and buoyant equity markets.

[Insert Tables 9 and 10 about here]

\section{Conclusion}

Recent literature has focused on the importance of market sentiment in empirical asset pricing. To capture this effect, Baker and Wurgler (2006) define an index constructed from the first principal component of the correlation matrix of a vector of proxies for investor sentiment. These authors find that waves of investor sentiment disproportionately affect securities with valuations that are highly subjective and difficult to arbitrage.

This paper has shifted the focus to bond markets. Our empirical analysis obtained from a long sample on US bond data covering the last four decades reveal that the dynamics of investor sentiment contain information for explaining bond risk premia, above and beyond that contained in the yield curve and macro factors used in the literature. Further, the out-of-sample performance of our pricing model that adds the investor sentiment factor to the single return-forecasting factors of Cochrane and Piazzesi (2005) and Ludvigson and Ng (2009) is superior to standard benchmark models. The contribution of market sentiment to explaining variations on bond excess returns is more important for periods of high sentiment.

These findings, along with existing evidence on the relevance of investor sentiment in asset markets, suggest that market sentiment has a prominent role for 
explaining systematic deviations in bond prices related to waves of market optimism and pessimism such as the flight to quality phenomenon between stocks and bonds. Investors require a higher premium on stocks than bonds when market sentiment is low and a lower premium when market sentiment is high. This mechanism operates through the choice of bonds compared to stocks in distress episodes that increases their relative demand and depresses the corresponding ex-post return. Similarly, the choice of stocks compared to bonds in periods of high sentiment increases its relative demand and depresses its ex-post return. Investor sentiment also reflects market expectations on future interest rate dynamics and monetary policy that are affecting the relative performance of the one-year bond vs. longer maturity bonds. In particular, low sentiment in the market signals future increases in interest rates that depress ex-post returns on long maturity bonds vs. the one year bond; similarly, high sentiment signals expectations of lower future interest rates that reflect increases in ex-post returns on long maturity bonds vs. the one year bond. 


\section{References}

[1] Baker, M., and Wurgler, J., 2006, Investor Sentiment and the Cross Section of Stock Returns, Journal of Finance, 61 (4), 1645-1680.

[2] Baker, M., and Wurgler, J., 2012, Comovement and Predictability Relationships between Bonds and the Cross-Section of Stocks, Review of Asset Pricing Studies, 2 (1), 57-87.

[3] Brandt M., Santa Clara P., Valkanov, R., 2009, Parametric Portfolio Policies Exploiting the Characteristics in the Cross Section of Equity Returns, Review of Financial Studies, 22, 3411-3447.

[4] Campbell, J. Y., Cochrane, J. H., 1999, By Force of Habit: A consumption-Based Explanation of Aggregate Stock Market Behavior, Journal of Political Economy, 107, 205-251.

[5] Campbell, J. Y., Shiller, R. J., 1991, Yield spreads and Interest Rate Movements: A Bird's Eye View, Review of Economic Studies, 58, 495-514.

[6] Chow, G. C., 1960, Tests of Equality Between Sets of Coefficients in Two Linear Regressions, Econometrica, 28 (3), 591-605.

[7] Cochrane, J. H., and Piazzesi, M., 2005, Bond Risk Premia, American Economic Review, 95(1), 138-160.

[8] Cooper, I., and Priestly, R., 2009, Time-Varying Risk Premiums and the Output Gap, Review of Financial Studies, 22 (7), 2801-2833.

[9] Dahlquist, M., and Hasseltoft, H., 2011, International Bond Risk Premia, Swiss Finance Institue Research Paper, 11-16.

[10] Diebold, F.X. and Mariano, R.S., 1995, Comparing Predictive Accuracy. Journal of Business and Economic Statistics, 13, 253-263.

[11] Duffie, G., 2011, Information in (and not in) the Term Structure, Review of Financial Studies, 24, 2895-2934.

[12] Fama, E.F., and Bliss, R.R., The Information in Long-Maturity Forward Rates, American Economic Review, 1987, 77(4), 680-92.

[13] Gurkaynak, R.S., Sack, B., and Wright, J.H., 2006, The U.S. Treasury Yield Curve: 1961 to the Present. Finance and Economics Discussion Series. WP. 2006-28. Federal Reserve Board, Washington, D.C.

[14] Hansen, L. P., and Hodrick, R. J. Risk Aversion Speculation in the Forward Foreign Exchange Market: An Econometric Analysis of Linear Models, in Jacob Frenkel, ed., Exchange rates and international macroeconomics. Chicago: University of Chicago Press, 1983. 
[15] Ludvigson, S.C., and Ng, S., 2009, Macro Factors in Bond Risk Premia, The Review of Financial Studies, 22(12), 5027-5067.

[16] Nayak, S. 2010, Investor Sentiment and Corporate Bond Yield Spreads, Review of Behavioral Finance, 2, 59-80.

[17] Newey, W. K., and West, K. D., 1987, A Simple, Positive Semidefinite, Heteroskedasticity and Autocorrelation Consistent Covariance Matrix, Econometrica, 55, 703-708. 


\section{Tables and Figures}

Table 1. Correlation of excess bond returns and explanatory variables.

\begin{tabular}{|c|c|c|c|c|c|c|c|c|c|}
\hline & $r x_{t+1}^{(2)}$ & $r x_{t+1}^{(3)}$ & $r x_{t+1}^{(4)}$ & $r x_{t+1}^{(5)}$ & $C P_{t}$ & $L N_{t}$ & $S_{t}^{\perp}$ & $S_{t}^{\perp 2}$ & $\Delta S_{t}^{\perp}$ \\
\hline$r x_{t+1}^{(2)}$ & 1 & & & & & & & & \\
\hline$r x_{t+1}^{(3)}$ & 0.98 & 1 & & & & & & & \\
\hline$r x_{t+1}^{(4)}$ & 0.96 & 0.99 & 1 & & & & & & \\
\hline$r x_{t+1}^{(5)}$ & 0.95 & 0.99 & 0.99 & 1 & & & & & \\
\hline$C P_{t}$ & 0.55 & 0.57 & 0.60 & 0.57 & 1 & & & & \\
\hline$L N_{t}$ & 0.49 & 0.48 & 0.46 & 0.44 & 0.37 & 1 & & & \\
\hline$S_{t}^{\perp}$ & 0.32 & 0.30 & 0.27 & 0.26 & 0.21 & 0.19 & 1 & & \\
\hline$S_{t}^{\perp 2}$ & 0.23 & 0.19 & 0.16 & 0.15 & 0.07 & 0.01 & 0.09 & 1 & \\
\hline$\Delta S_{t}^{\perp}$ & -0.39 & -0.40 & -0.40 & -0.40 & -0.31 & -0.30 & -0.04 & -0.001 & 1 \\
\hline
\end{tabular}

Notes: The table reports correlations of excess bond returns on the 12 month lagged variables used in eqn 15, breaking down the underlying investor sentiment factor into the variables that define it (eqn. 14). The variable $r x_{t+1}^{(n)}$ is the excess return on the $n$-year Treasury bond. $\mathrm{CP}_{\mathrm{t}}$ is the Cochrane and Piazzesi (2005) factor that is a linear combination of five forward rates (eqn. 9). $\mathrm{LN}_{\mathrm{t}}$ is the Ludvigson and $\mathrm{Ng}$ macro factor (2009) that is a combination of five factors estimated by the method of principal factor applied to a panel of of data with 132 individual series (eqn 12 with $F_{2 t}$ dropped). $S_{t}^{\perp}$ is the investor sentiment variable defined in Baker and Wurgler (2006) which is a combination of six proxies for sentiment and $\Delta S_{t}^{\perp}$ is the annual change of $S_{t}^{\perp}$. The sample spans the period 1965:82007:12. 
Table 2. Estimates of the Cochrane and Piazzesi model (2005).

\begin{tabular}{|c|c|c|c|c|c|c|c|c|c|c|c|c|}
\hline \multicolumn{13}{|c|}{ Unrestricted model. $r x_{t+1}^{(n)}=\beta_{0}+\beta_{1} y_{t}^{1}+\beta_{2} f_{t}^{1 \rightarrow 2}+\beta_{3} f_{t}^{2 \rightarrow 3}+\beta_{4} f_{t}^{3-4}+\beta_{5} f_{t}^{4 \rightarrow 5}+\varepsilon_{t+1}^{(n)}$} \\
\hline & & $\mathrm{n}$ & $\beta_{0}$ & $\beta_{1}$ & $\beta_{2}$ & $\beta_{3}$ & $\beta_{4}$ & $\beta_{5}$ & $\mathrm{R}^{2}$ & \multicolumn{2}{|c|}{$95 \%$ confidence } & $\chi^{2}(5)$ \\
\hline \multicolumn{2}{|c|}{ coef } & 2 & -1.59 & -0.89 & 0.43 & 1.89 & 0.334 & -0.83 & 0.31 & $\lceil 0.18$ & 0.521 & 100.93 \\
\hline \multicolumn{2}{|c|}{ s.e } & & $(0.68)$ & $(0.16)$ & $(0.38)$ & $(0.31)$ & $(0.20)$ & $(0.19)$ & & & & \\
\hline \multicolumn{2}{|c|}{ small s.e } & & $(0.84)$ & $(0.30)$ & $(0.50)$ & $(0.40)$ & $(0.29)$ & $(0.27)$ & & & & \\
\hline \multicolumn{2}{|c|}{ coef } & 3 & -2.56 & -1.61 & 0.28 & 3.02 & 0.46 & -1.77 & 0.32 & 「0.20 & 0.531 & 99.34 \\
\hline \multicolumn{2}{|c|}{ s.e } & & $(1.25)$ & $(0.30)$ & $(0.61)$ & $(0.50)$ & $(0.39)$ & $(0.31)$ & & & & \\
\hline \multicolumn{2}{|c|}{ small s.e } & & $(1.51)$ & $(0.53)$ & (0.89) & $(0.70)$ & $(0.53)$ & $(0.50)$ & & & & \\
\hline \multicolumn{2}{|c|}{ coef } & 4 & -3.55 & -2.38 & 0.54 & 3.51 & 1.374 & -2.61 & 0.36 & $\lceil 0.22$ & 0.551 & 100.48 \\
\hline \multicolumn{2}{|c|}{ s.e } & & $(1.72)$ & $(0.43)$ & $(0.77)$ & $(0.63)$ & $(0.64)$ & $(0.41)$ & & & & \\
\hline \multicolumn{2}{|c|}{ small s.e } & & $(2.02)$ & $(0.71)$ & (1.19) & $(0.93)$ & $(0.93)$ & $(0.68)$ & & & & \\
\hline \multicolumn{2}{|c|}{ coef } & 5 & -4.53 & -2.98 & 0.84 & 3.97 & 1.36 & -2.67 & 0.33 & Г0.19 & 0.531 & 76.05 \\
\hline \multicolumn{2}{|c|}{ s.e } & & $(2.14)$ & $(0.53)$ & $(0.90)$ & $(0.72)$ & $(0.61)$ & $(0.51)$ & & & & \\
\hline \multicolumn{2}{|c|}{ small s.e } & & $(2.48)$ & $(0.88)$ & (1.47) & $(1.15)$ & $(0.87)$ & $(0.84)$ & & & & \\
\hline \multicolumn{13}{|c|}{ Restricted model. Two step procedure. } \\
\hline \multicolumn{13}{|c|}{ 1) Estimates of the return forecasting model. $\overline{r x}_{t+1}=\lambda_{0}+\lambda_{1} y_{t}^{1}+\lambda_{2} f_{t}^{1 \rightarrow 2}+\lambda_{3} f_{t}^{2 \rightarrow 3}+\lambda_{4} f_{t}^{3 \rightarrow 4}+\lambda_{5} f_{t}^{4 \rightarrow 5}+u_{t+1}$} \\
\hline & $\lambda_{0}$ & $\lambda_{1}$ & $\lambda_{2}$ & $\lambda_{3}$ & $\lambda_{4}$ & $\lambda_{5}$ & & $\mathrm{R}^{2}$ & & $95 \%$ confid & e interval & $\chi^{2}(5)$ \\
\hline coef & -3.06 & -1.98 & 0.52 & 2.92 & 0.88 & -1.97 & & 0.33 & & {$[0.20$} & $0.55]$ & 91.11 \\
\hline s.e & $(1.43)$ & $(0.35)$ & $(0.65)$ & $(0.54)$ & $(0.42)$ & $(0.35)$ & & & & & & \\
\hline small & $(1.70)$ & $(0.60)$ & $(1.01)$ & $(0.79)$ & $(0.60)$ & $(0.57)$ & & & & & & \\
\hline
\end{tabular}

2) Individual bond regressions. $r x_{t+1}^{(n)}=b_{n}\left(\lambda_{0}+\lambda_{1} y_{t}^{1}+\lambda_{2} f_{t}^{1 \rightarrow 2}+\lambda_{3} f_{t}^{2 \rightarrow 3}+\lambda_{4} f_{t}^{3 \rightarrow 4}+\lambda_{5} f_{t}^{4 \rightarrow 5}\right)+\varepsilon_{t+1}^{(n)}$

\begin{tabular}{|c|c|c|c|c|c|}
\hline \multirow{2}{*}{$\begin{array}{c}\text { bn } \\
0.46\end{array}$} & \multirow{2}{*}{$\begin{array}{c}\text { gmm s.e } \\
(0.03)\end{array}$} & \multirow{2}{*}{$\begin{array}{c}\text { small s.e } \\
(0.02)\end{array}$} & \multirow{2}{*}{$\begin{array}{c}\mathrm{R} 2 \\
0.29\end{array}$} & \multicolumn{2}{|c|}{$\begin{array}{c}95 \% \\
\text { confidence } \\
\text { interval }\end{array}$} \\
\hline & & & & {$[0.16$} & $0.51]$ \\
\hline 0.87 & $(0.02)$ & $(0.02)$ & 0.32 & {$[0.19$} & $0.54]$ \\
\hline 1.23 & $(0.01)$ & $(0.01)$ & 0.35 & {$[0.22$} & $0.55]$ \\
\hline 1.43 & $(0.04)$ & $(0.03)$ & 0.32 & {$[0.19$} & $0.53]$ \\
\hline
\end{tabular}

Notes: The unrestricted model reports estimates from OLS regressions of excess bond returns on the forward rates. The dependent variable $r x_{t+1}^{n}$ is the excess return on the n-year Treasury bond. Hansen and Hodrick and bootstrap standard errors are reported in parentheses. The restricted model reports estimates from OLS regressions of excess bond returns on the $\mathrm{CP}_{\mathrm{t}}$ factor. The sample spans the period 1965:8-2007:12. 
Table 3. Estimates of the investor sentiment model.

\begin{tabular}{|c|c|c|c|c|c|c|c|c|c|}
\hline \multicolumn{10}{|c|}{ Unrestricted model, $r x_{t+1}^{(n)}=\beta_{0}+\beta_{1} S_{t}^{\perp}+\beta_{2} S_{t}^{\perp 2}+\beta_{3} \Delta S_{t}^{\perp}+\varepsilon_{t+1}^{n}$} \\
\hline & $\mathrm{n}$ & $\beta_{0}$ & $\bar{\beta}$ & $\beta_{2}$ & $\beta_{3}$ & $\mathrm{R}^{2}$ & \multicolumn{2}{|c|}{$95 \%$ confidence interval } & $\chi^{2}(3)$ \\
\hline \multirow{3}{*}{$\begin{array}{c}\text { coef } \\
\text { s.e } \\
\text { small s.e }\end{array}$} & 2 & 0.21 & 0.55 & 0.24 & -0.084 & 0.14 & {$[0.00$} & $0.22]$ & 9.42 \\
\hline & & $(0.33)$ & $(0.28)$ & $(0.17)$ & $(0.04)$ & & & & \\
\hline & & $(0.23)$ & $(0.38)$ & $(0.17)$ & $(0.07)$ & & & & \\
\hline \multirow{3}{*}{$\begin{array}{c}\text { coef } \\
\text { s.e } \\
\text { small s.e }\end{array}$} & 3 & 0.41 & 0.95 & 0.33 & -0.16 & 0.12 & {$[0.00$} & $0.21]$ & 8.44 \\
\hline & & $(0.60)$ & $(0.49)$ & $(0.28)$ & $(0.07)$ & & & & \\
\hline & & $(0.41)$ & $(0.69)$ & $(0.31)$ & $(0.14)$ & & & & \\
\hline \multirow{2}{*}{$\begin{array}{c}\text { coef } \\
\text { s.e }\end{array}$} & 4 & 0.58 & 1.19 & 0.39 & -0.23 & 0.10 & {$[0.00$} & $0.21]$ & 7.05 \\
\hline & & $(0.85)$ & $(0.65)$ & $(0.38)$ & $(0.11)$ & & & & \\
\hline small s.e & & $(0.56)$ & $(0.95)$ & $(0.42)$ & $(0.20)$ & & & & \\
\hline \multirow{2}{*}{$\begin{array}{c}\text { coef } \\
\text { s.e }\end{array}$} & 5 & 0.53 & 1.38 & 0.42 & -0.32 & 0.08 & {$[0.00$} & $0.21]$ & 7.32 \\
\hline & & (1.03) & $(0.78)$ & $(0.46)$ & $(0.14)$ & & & & \\
\hline small s.e & & $(0.68)$ & $(1.15)$ & $(0.51)$ & $(0.24)$ & & & & \\
\hline
\end{tabular}

Restricted model. Two step procedure.

1) Estimates of the return forecasting model. $\quad \overline{r x}_{t+1}=\phi_{0}+\phi_{1} S_{t}^{\perp}+\phi_{2} S_{t}^{\perp 2}+\phi_{3} \Delta S_{t}^{\perp}+\tau_{t+1}$

\begin{tabular}{cccccccc}
\hline & $\phi_{0}$ & $\phi_{1}$ & $\phi_{2}$ & $\phi_{3}$ & $\mathrm{R}^{2}$ & $95 \%$ confidence interval & $\chi^{2}(3)$ \\
\hline coef & 0.44 & 1.01 & 0.34 & -0.20 & 0.10 & {$[0.00$} & $0.21]$ \\
s.e & $(0.70)$ & $(0.55)$ & $(0.32)$ & $(0.08)$ & & \\
\multirow{2}{*}{ small s.e } & $(0.47)$ & $(0.79)$ & $(0.35)$ & $(0.16)$ & & \\
\hline
\end{tabular}

2) Individual bond regressions. $\quad r x_{t+1}^{(n)}=b_{n}\left(\phi_{0}+\phi_{1} S_{t}^{\perp}+\phi_{2} S_{t}^{\perp 2}+\phi_{3} \Delta S_{t}^{\perp}\right)+\varepsilon_{t+1}^{n}$

\begin{tabular}{cccccc}
\hline bn & gmm s.e & small s.e & R2 & 95\% confidence interval \\
\hline 0.56 & $(0.05)$ & $(0.07)$ & 0.14 & {$[0.00$} & $0.21]$ \\
0.94 & $(0.04)$ & $(0.05)$ & 0.12 & {$[0.00$} & $0.21]$ \\
1.18 & $(0.03)$ & $(0.03)$ & 0.10 & {$[0.00$} & $0.21]$ \\
1.31 & $(0.07)$ & $(0.10)$ & 0.08 & {$[0.00$} & $0.21]$ \\
\hline
\end{tabular}

Notes: The unrestricted model reports estimates from OLS regressions of excess bond returns on the investor sentiment variables. The dependent variable $r x_{t+1}^{n}$ is the excess return on the n-year Treasury bond. $\mathrm{S}_{\mathrm{t}} \perp$ is the investor sentiment variable defined in Baker and Wurgler (2006) and $\Delta \mathrm{S}_{t}^{\perp}$ is the annual change of $\mathrm{S}_{\mathrm{t}} \perp$. Hansen and Hodrick standard errors and bootstrap standard errors are reported in parentheses. The restricted model reports estimates from OLS regressions of excess bond returns on the $\mathrm{BW}_{\mathrm{t}}$ factor. The sample spans the period 1965:82007:12. 
Table 4. GMM tests of the investor sentiment model.

\begin{tabular}{|c|c|c|c|c|c|c|c|c|c|}
\hline \multirow[b]{2}{*}{ Lag i } & \multirow[b]{2}{*}{ Test } & \multicolumn{2}{|c|}{$\mathrm{NW}, 18$} & \multicolumn{2}{|c|}{ No overlap } & \multicolumn{2}{|c|}{$\underline{\text { Simple S }}$} & \multicolumn{2}{|c|}{ Small Sample } \\
\hline & & $\chi^{2}$ & $\mathrm{p}$-value & $\chi^{2}$ & p-value & $\chi^{2}$ & p-value & $x^{2}$ & p-value \\
\hline 0 & $\mathrm{~J}_{\mathrm{T}}$ & 27.431 & 0.02 & 5.547 & 0.98 & 3.661 & 0.99 & 13.93 & 0.53 \\
\hline 0 & Wald & 39.076 & 0.06 & 6.264 & 0.97 & 4.131 & 0.99 & 20.96 & 0.18 \\
\hline 1 & $\mathrm{~J}_{\mathrm{T}}$ & 21.564 & 0.11 & 127 & 1.00 & 761 & 1.00 & 12.29 & 0.66 \\
\hline 1 & Wald & 31.527 & 0.75 & 5.898 & 0.98 & 3.638 & 0.99 & 16.46 & 0.42 \\
\hline 2 & $\mathrm{~J}_{\mathrm{T}}$ & 21.259 & 0.12 & 104 & 1.00 & 141 & 1.00 & 12.53 & 0.64 \\
\hline 2 & Wald & 41.368 & 0.03 & 5.125 & 1.00 & 3.582 & 0.99 & 5.12 & 1.00 \\
\hline
\end{tabular}

Notes: $\mathrm{J}_{\mathrm{T}}$ and Wald tests proposed by Cochrane and Piazzesi (2005) of the investor sentiment model against the unrestricted model. The 5 percent critical values for all the tests is 24.96 . 
Table 5. Estimates of the Ludvigson and Ng macro factor model (2009).

\begin{tabular}{|c|c|c|c|c|c|c|c|c|c|c|c|}
\hline \multicolumn{12}{|c|}{ Unrestricted model, $r x_{t+1}^{(n)}=\beta_{0}+\beta_{1} F_{1 t}+\beta_{2} F_{1 t}^{3}+\beta_{3} F_{3 t}+\beta_{4} F_{4 t}+\beta_{5} F_{8 t}+\varepsilon_{t+1}^{(n)}$} \\
\hline & $\mathrm{n}$ & $\beta_{0}$ & $\beta_{1}$ & $\beta_{2}$ & $\beta_{3}$ & $\beta_{4}$ & $\beta_{5}$ & $\mathrm{R}^{2}$ & \multicolumn{2}{|c|}{$95 \%$ confidence interval } & $\chi^{2}(5)$ \\
\hline coef & 2 & 0.51 & 0.90 & -0.05 & -0.04 & -0.41 & 0.30 & 0.23 & {$[0.00$} & $0.13]$ & 34.9 \\
\hline s.e & & $(0.26)$ & $(0.20)$ & $(0.02)$ & $(0.05)$ & $(0.16)$ & $(0.09)$ & & & & \\
\hline small s.e & & $(0.13)$ & $(0.28)$ & $(0.02)$ & $(0.07)$ & $(0.21)$ & $(0.14)$ & & & & \\
\hline coef & 3 & 0.869 & 1.53 & -0.10 & 0.01 & -0.61 & 0.56 & 0.18 & {$[0.00$} & $0.13]$ & 31.2 \\
\hline s.e & & $(0.47)$ & $(0.35)$ & $(0.03)$ & $(0.11)$ & $(0.30)$ & $(0.18)$ & & & & \\
\hline small s.e & & $(0.22)$ & $(0.51)$ & $(0.03)$ & $(0.12)$ & $(0.31)$ & $(0.25)$ & & & & \\
\hline coef & 4 & 1.13 & 1.95 & -0.14 & 0.04 & -0.70 & 0.84 & 0.16 & {$[0.00$} & $0.12]$ & 29.26 \\
\hline s.e & & $(0.66)$ & $(0.46)$ & $(0.04)$ & $(0.17)$ & $(0.45)$ & $(0.25)$ & & & & \\
\hline small s.e & & $(0.31)$ & $(0.71)$ & $(0.05)$ & $(0.17)$ & $(0.52)$ & $(0.34)$ & & & & \\
\hline coef & 5 & 1.14 & 2.15 & -0.15 & 0.10 & -0.84 & 1.01 & 0.14 & {$[0.00$} & $0.12]$ & 26.8 \\
\hline s.e & & $(0.81)$ & $(0.56)$ & $(0.05)$ & $(0.21)$ & $(0.56)$ & $(0.31)$ & & & & \\
\hline small s.e & & $(0.37)$ & $(0.85)$ & $(0.06)$ & $(0.21)$ & $(0.63)$ & $(0.42)$ & & & & \\
\hline
\end{tabular}

\begin{tabular}{|c|c|c|c|c|c|c|c|c|c|c|}
\hline \multicolumn{11}{|c|}{ Restricted model. Two step procedure. } \\
\hline \multicolumn{11}{|c|}{ 1) Estimates of the return forecasting model. $\overline{r x}_{t+1}=\theta_{0}+\theta_{1} F_{1 t}+\theta_{2} F_{1 t}^{3}+\theta_{3} F_{3 t}+\theta_{4} F_{4 t}+\theta_{5} F_{8 t}+v_{t+1}$} \\
\hline & $\theta_{0}$ & $\theta_{1}$ & $\theta_{2}$ & $\theta_{3}$ & $\theta_{4}$ & $\theta_{5}$ & $\mathrm{R}^{2}$ & \multicolumn{2}{|c|}{$95 \%$ confidence interval } & $\chi^{2}(5)$ \\
\hline coef & 0.91 & 1.63 & -0.11 & 0.02 & -0.63 & 0.67 & 0.17 & {$[0.00$} & $0.12]$ & 29.35 \\
\hline s.e & $(0.55)$ & $(0.39)$ & $(0.03)$ & $(0.14)$ & $(0.37)$ & $(0.21)$ & & & & \\
\hline small s.e & $(0.25)$ & $(0.58)$ & $(0.04)$ & $(0.14)$ & $(0.44)$ & $(0.28)$ & & & & \\
\hline
\end{tabular}

2) Individual bond regressions. $\left.r x_{t+1}^{(n)}=b_{n}\left(\theta_{0}+\theta_{1} F_{1 t}+\theta_{2} F_{1 t}^{3}+\theta_{3} F_{3 t}+\theta_{5} F_{4 t}+\theta_{6} F_{8 t}\right)+\right) \varepsilon_{t+1}^{(n)}$

\begin{tabular}{|c|c|c|c|c|c|}
\hline bn & gmm s.e & small s.e & R2 & \multicolumn{2}{|c|}{$95 \%$ confidence interval } \\
\hline 0.55 & $(0.02)$ & $(0.06)$ & 0.22 & {$[0.00$} & $0.12]$ \\
\hline 0.93 & $(0.01)$ & $(0.04)$ & 0.19 & {$[0.00$} & $0.12]$ \\
\hline 1.19 & $(0.02)$ & $(0.01)$ & 0.16 & {$[0.00$} & $0.12]$ \\
\hline 1.32 & $(0.03)$ & $(0.01)$ & 0.14 & {$[0.00$} & $0.12]$ \\
\hline
\end{tabular}

Notes: The unrestricted model reports estimates from OLS regressions of excess bond returns on the Ludvigson and

Ng macro factors (2009). The dependent variable $r x_{t+1}^{n}$ is the excess return on the n-year Treasury bond. Hansen and Hodrick and bootstrap standard errors are reported in parentheses. The restricted model reports estimates from OLS regressions of excess bond returns on the $\mathrm{LN}_{\mathrm{t}}$ factor. The sample spans the period 1966:7-2007:12. 
Table 6. Regressions of monthly excess bond returns on lagged factors.

\begin{tabular}{|c|c|c|c|c|c|c|c|c|}
\hline & \multirow{2}{*}{$\begin{array}{l}\mathrm{n} \\
2\end{array}$} & \multirow{2}{*}{$\begin{array}{c}\mathrm{CP}_{\mathrm{t}} \\
\\
0.37 \\
(0.07)\end{array}$} & \multirow{2}{*}{$\begin{array}{c}\mathrm{LN}_{\mathrm{t}} \\
\\
0.40 \\
(0.07)\end{array}$} & \multirow[t]{2}{*}{$\mathrm{BW}_{\mathrm{t}}$} & \multirow{2}{*}{$\begin{array}{c}\mathrm{R}^{2} \\
0.43\end{array}$} & \multicolumn{2}{|c|}{$95 \%$ confidence interval } & \multirow[t]{2}{*}{ Partial $\mathrm{R}^{2}$} \\
\hline & & & & & & {$[0.00$} & $0.51]$ & \\
\hline small s.e & & $(0.10)$ & $(0.14)$ & & & & & \\
\hline Coef & & 0.35 & 0.35 & 0.19 & 0.45 & {$[0.00$} & $0.46]$ & \\
\hline s.e & & $(0.07)$ & $(0.07)$ & $(0.12)$ & & & & \\
\hline small s.e & & $(0.10)$ & $(0.15)$ & $(0.23)$ & & & & \\
\hline Coef & 3 & 0.72 & 0.63 & & 0.42 & {$[0.00$} & $0.51]$ & \\
\hline s.e & & $(0.14)$ & $(0.14)$ & & & & & \\
\hline small s.e & & $(0.19)$ & $(0.25)$ & & & & & \\
\hline Coef & & 0.68 & 0.55 & 0.27 & 0.43 & {$[0.00$} & $0.47]$ & \\
\hline s.e & & $(0.14)$ & $(0.13)$ & $(0.22)$ & & & & \\
\hline small s.e & & $(0.20)$ & $(0.28)$ & $(0.43)$ & & & & \\
\hline Coef & 4 & 1.06 & 0.76 & & 0.42 & {$[0.00$} & $0.51]$ & \\
\hline & & $(0.20)$ & $(0.18)$ & & & & & \\
\hline small s.e & & $(0.26)$ & $(0.34)$ & & & & & \\
\hline Coef & & 1.03 & 0.70 & 0.24 & 0.43 & {$[0.00$} & $0.46]$ & \\
\hline s.e & & $(0.20)$ & $(0.18)$ & $(0.30)$ & & & & \\
\hline small s.e & & $(0.26)$ & $(0.39)$ & $(0.60)$ & & & & \\
\hline Coef & 5 & 1.24 & 0.82 & & 0.38 & {$[0.00$} & $0.41]$ & \\
\hline & & $(0.26)$ & $(0.21)$ & & & & & \\
\hline small s.e & & $(0.32)$ & $(0.41)$ & & & & & \\
\hline Coef & & 1.21 & 0.75 & 0.23 & 0.39 & {$[0.00$} & $0.38]$ & \\
\hline & & $(0.25)$ & $(0.21)$ & $(0.36)$ & & & & \\
\hline small s.e & & $(0.32)$ & $(0.47)$ & $(0.73)$ & & & & \\
\hline Coef & $\overline{r x}_{t+1}$ & 1 & & & & & & 0.33 \\
\hline Coef & $\overline{r x}_{t+1}$ & 0.85 & 0.65 & & & & & 0.41 \\
\hline Coef & $\overline{r x}_{t+1}$ & 0.81 & 0.58 & 0.23 & & & & 0.43 \\
\hline
\end{tabular}

Notes: The table reports estimates from OLS regressions of excess bond returns on the lagged variables named in row 1. The dependent variable is the excess return on the n-year Treasury bond. $\mathrm{CP}_{\mathrm{t}}$ is the Cochrane and Piazzesi (2005) factor that is a linear combination of five forward rates. $\mathrm{LN}_{\mathrm{t}}$ is the Ludvigson and $\mathrm{Ng}$ macro factor (2009) that is a combination of six factors estimated by the method of principal factor applied to a panel of of data with 132 individual series. $\mathrm{BW}_{\mathrm{t}}$ is the investor sentiment factor (see eqn. 14) that is a linear combination of variables related to the sentiment index defined in Baker and Wurgler (2006). Hansen and Hodrick standard errors and bootstrap standard errors are reported in parentheses. The sample spans the period 1965:8-2007:12. 
Table 7. Regressions of monthly excess bond returns on lagged factors. Subsample analysis.

\begin{tabular}{|c|c|c|c|c|c|c|}
\hline \multicolumn{7}{|c|}{$1965: 8-1969: 12$} \\
\hline & $\mathrm{N}$ & $\mathrm{CP}_{\mathrm{t}}$ & $\mathrm{LN}_{\mathrm{t}}$ & $\mathrm{BW}_{\mathrm{t}}$ & $\mathrm{R}^{2}$ & Partial $\mathrm{R}^{2}$ \\
\hline Coef & 2 & 0.54 & 0.003 & & 0.09 & \\
\hline s.e & & $(0.02)$ & $(0.19)$ & & & \\
\hline Coef & & 0.41 & -0.001 & -0.35 & 0.23 & \\
\hline s.e & & $(0.14)$ & $(0.22)$ & $(0.24)$ & & \\
\hline Coef & 3 & 1.05 & -0.02 & & 0.21 & \\
\hline s.e & & $(0.11)$ & $(0.22)$ & & & \\
\hline Coef & & 0.72 & -0.02 & -0.88 & 0.35 & \\
\hline s.e & & $(0.11)$ & $(0.28)$ & $(0.25)$ & & \\
\hline Coef & 4 & 1.46 & -0.03 & & 0.14 & \\
\hline s.e & & $(0.17)$ & $(0.38)$ & & & \\
\hline Coef & & 0.99 & -0.04 & -1.28 & 0.31 & \\
\hline s.e & & $(0.24)$ & $(0.46)$ & $(0.48)$ & & \\
\hline Coef & 5 & 1.82 & 0.02 & & 0.01 & \\
\hline s.e & & $(0.21)$ & $(0.53)$ & & & \\
\hline Coef & & 1.26 & 0.002 & -1.48 & 0.15 & \\
\hline s.e & & $(0.42)$ & $(0.62)$ & $(0.79)$ & & \\
\hline Coef & $\overline{r x}_{t+1}$ & 1.22 & & & & 0.08 \\
\hline Coef & $\overline{r x}_{t+1}$ & 1.22 & -0.006 & & & 0.08 \\
\hline Coef & $\overline{r x}_{t+1}$ & 0.85 & -0.01 & -1.00 & & 0.23 \\
\hline \multicolumn{7}{|c|}{ 1970:1-1979:12 } \\
\hline & $\mathrm{N}$ & $\mathrm{CP}_{\mathrm{t}}$ & $\mathrm{LN}_{\mathrm{t}}$ & $\mathrm{BW}_{\mathrm{t}}$ & $\mathrm{R}^{2}$ & Partial $\mathrm{R}^{2}$ \\
\hline Coef & 2 & 0.25 & 0.52 & & 0.41 & \\
\hline s.e & & $(0.09)$ & $(0.14)$ & & & \\
\hline Coef & & 0.20 & 0.43 & 0.40 & 0.45 & \\
\hline s.e & & $(0.11)$ & $(0.09)$ & $(0.10)$ & & \\
\hline Coef & 3 & 0.48 & 0.78 & & 0.39 & \\
\hline s.e & & $(0.15)$ & $(0.25)$ & & & \\
\hline Coef & & 0.39 & 0.59 & 0.83 & 0.47 & \\
\hline s.e & & $(0.18)$ & $(0.15)$ & $(0.18)$ & & \\
\hline Coef & 4 & 0.64 & 0.98 & & 0.41 & \\
\hline s.e & & $(0.19)$ & $(0.31)$ & & & \\
\hline Coef & & 0.52 & 0.73 & 1.07 & 0.48 & \\
\hline s.e & & $(0.23)$ & $(0.18)$ & $(0.22)$ & & \\
\hline Coef & 5 & 0.72 & 1.15 & & 0.38 & \\
\hline s.e & & $(0.25)$ & $(0.38)$ & & & \\
\hline Coef & & 0.58 & 0.86 & 1.25 & 0.45 & \\
\hline s.e & & $(0.29)$ & $(0.25)$ & $(0.30)$ & & \\
\hline Coef & $\overline{r x}_{t+1}$ & 0.59 & & & & 0.14 \\
\hline Coef & $\overline{r x}_{t+1}$ & 0.52 & 0.86 & & & 0.40 \\
\hline Coef & $\overline{r x}_{t+1}$ & 0.42 & 0.62 & 0.88 & & 0.48 \\
\hline \multicolumn{7}{|c|}{$2000: 1-2007: 12$} \\
\hline & $\mathrm{N}$ & $\mathrm{CP}_{\mathrm{t}}$ & $\mathrm{LN}_{\mathrm{t}}$ & $\mathrm{BW}_{\mathrm{t}}$ & $\mathrm{R}^{2}$ & Partial R ${ }^{2}$ \\
\hline Coef & 2 & 0.21 & 0.61 & & 0.44 & \\
\hline s.e & & $(0.17)$ & $(0.11)$ & & & \\
\hline Coef & & 0.24 & 0.32 & 0.44 & 0.55 & \\
\hline s.e & & $(0.12)$ & $(0.09)$ & $(0.18)$ & & \\
\hline Coef & 3 & 0.46 & 1.15 & & 0.43 & \\
\hline s.e & & $(0.34)$ & $(0.13)$ & & & \\
\hline Coef & & 0.50 & 0.69 & 0.70 & 0.51 & \\
\hline s.e & & $(0.27)$ & $(0.19)$ & $(0.32)$ & & \\
\hline Coef & 4 & 0.72 & 1.46 & & 0.42 & \\
\hline s.e & & $(0.47)$ & $(0.10)$ & & & \\
\hline Coef & & 0.75 & 0.96 & 0.74 & 0.47 & \\
\hline s.e & & $(0.39)$ & $(0.26)$ & $(0.40)$ & & \\
\hline Coef & 5 & 0.93 & 1.62 & & 0.38 & \\
\hline s.e & & $(0.56)$ & $(0.07)$ & & & \\
\hline Coef & & 0.97 & 1.11 & 0.75 & 0.42 & \\
\hline s.e & & $(0.48)$ & $(0.33)$ & $(0.48)$ & & \\
\hline Coef & $\overline{r x}_{t+1}$ & 0.85 & & & & 0.13 \\
\hline Coef & $\overline{r x}_{t+1}$ & 0.58 & 1.21 & & & 0.42 \\
\hline Coef & $\overline{r x}_{t+1}$ & 0.61 & 0.77 & 0.66 & & 0.49 \\
\hline
\end{tabular}




\begin{tabular}{|c|c|c|c|c|c|c|}
\hline \multicolumn{7}{|c|}{$1965: 8-1979: 8$} \\
\hline & $\mathrm{n}$ & $\mathrm{CP}_{\mathrm{t}}$ & $\mathrm{LN}_{\mathrm{t}}$ & $\mathrm{BW}_{\mathrm{t}}$ & $\mathrm{R}^{2}$ & Partial $\mathrm{R}^{2}$ \\
\hline Coef & 2 & 0.31 & 0.44 & & 0.36 & \\
\hline s.e & & $(0.08)$ & $(0.12)$ & & & \\
\hline Coef & & 0.33 & 0.40 & 0.11 & 0.38 & \\
\hline s.e & & $(0.09)$ & $(0.11)$ & $(0.08)$ & & \\
\hline Coef & 3 & 0.62 & 0.66 & & 0.38 & \\
\hline s.e & & $(0.16)$ & $(0.22)$ & & & \\
\hline Coef & & 0.64 & 0.60 & 0.19 & 0.40 & \\
\hline s.e & & $(0.18)$ & $(0.19)$ & $(0.17)$ & & \\
\hline Coef & 4 & 0.88 & 0.82 & & 0.39 & \\
\hline s.e & & $(0.24)$ & $(0.28)$ & & & \\
\hline Coef & & 0.90 & 0.78 & 0.14 & 0.40 & \\
\hline s.e & & $(0.25)$ & $(0.26)$ & $(0.25)$ & & \\
\hline Coef & 5 & 1.04 & 0.97 & & 0.35 & \\
\hline s.e & & $(0.30)$ & $(0.34)$ & & & \\
\hline Coef & & 1.05 & 0.94 & 0.10 & 0.36 & \\
\hline s.e & & $(0.29)$ & $(0.34)$ & $(0.31)$ & & \\
\hline Coef & $\overline{r x}_{t+1}$ & 0.76 & & & & 0.22 \\
\hline Coef & $\overline{r x}_{t+1}$ & 0.71 & 0.72 & & & 0.38 \\
\hline Coef & $\overline{r x}_{t+1}$ & 0.73 & 0.69 & 0.14 & & 0.39 \\
\hline \multicolumn{7}{|c|}{ 1979:9-1982:10 } \\
\hline & $\mathrm{n}$ & $\mathrm{CP}_{\mathrm{t}}$ & $\mathrm{LN}_{\mathrm{t}}$ & $\mathrm{BW}_{\mathrm{t}}$ & $\mathrm{R}^{2}$ & Partial $\mathrm{R}^{2}$ \\
\hline Coef & 2 & 0.15 & -0.09 & & 0.36 & \\
\hline s.e & & $(0.05)$ & $(0.02)$ & & & \\
\hline Coef & & 0.18 & 0.17 & -0.84 & 0.38 & \\
\hline s.e & & $(0.09)$ & $(0.11)$ & $(0.18)$ & & \\
\hline Coef & 3 & 0.41 & -0.32 & & 0.38 & \\
\hline s.e & & $(0.26)$ & $(0.30)$ & & & \\
\hline Coef & & 0.46 & 0.21 & -1.76 & 0.40 & \\
\hline s.e & & $(0.11)$ & $(0.13)$ & $(0.28)$ & & \\
\hline Coef & 4 & 0.74 & -0.53 & & 0.39 & \\
\hline s.e & & $(0.32)$ & $(0.41)$ & & & \\
\hline Coef & & 0.81 & 0.23 & -2.52 & 0.40 & \\
\hline s.e & & $(0.09)$ & $(0.18)$ & $(0.33)$ & & \\
\hline Coef & 5 & 0.86 & -0.81 & & 0.35 & \\
\hline s.e & & $(0.47)$ & $(0.57)$ & & & \\
\hline Coef & & 0.95 & 0.14 & -3.16 & 0.35 & \\
\hline s.e & & $(0.24)$ & $(0.19)$ & $(0.32)$ & & \\
\hline Coef & $\overline{r x}_{t+1}$ & 0.64 & & & & 0.22 \\
\hline Coef & $\overline{r x}_{t+1}$ & 0.54 & -0.44 & & & 0.38 \\
\hline Coef & $\overline{r x}_{t+1}$ & 0.60 & 0.18 & -2.07 & & 0.39 \\
\hline \multicolumn{7}{|c|}{ 1982:10-2007:12 } \\
\hline & $\mathrm{n}$ & $\mathrm{CP}_{\mathrm{t}}$ & $\mathrm{LN}_{\mathrm{t}}$ & $\mathrm{BW}_{\mathrm{t}}$ & $\mathrm{R}^{2}$ & Partial $\mathrm{R}^{2}$ \\
\hline Coef & 2 & 0.39 & 0.37 & & 0.33 & \\
\hline s.e & & $(0.12)$ & $(0.12)$ & & & \\
\hline Coef & & 0.27 & 0.28 & 0.42 & 0.41 & \\
\hline s.e & & $(0.09)$ & $(0.13)$ & $(0.17)$ & & \\
\hline Coef & 3 & 0.70 & 0.64 & & 0.31 & \\
\hline s.e & & $(0.24)$ & $(0.21)$ & & & \\
\hline Coef & & 0.53 & 0.52 & 0.63 & 0.36 & \\
\hline s.e & & $(0.19)$ & $(0.20)$ & $(0.30)$ & & \\
\hline Coef & 4 & 1.05 & 0.78 & & 0.31 & \\
\hline s.e & & $(0.34)$ & $(0.27)$ & & & \\
\hline Coef & & 0.87 & 0.65 & 0.69 & 0.35 & \\
\hline s.e & & $(0.28)$ & $(0.28)$ & $(0.40)$ & & \\
\hline Coef & 5 & 1.24 & 0.78 & & 0.27 & \\
\hline s.e & & $(0.43)$ & $(0.31)$ & & & \\
\hline Coef & & 1.04 & 0.63 & 0.75 & 0.30 & \\
\hline s.e & & $(0.35)$ & $(0.32)$ & $(0.46)$ & & \\
\hline Coef & $\overline{r x}_{t+1}$ & 1.01 & & & & 0.22 \\
\hline Coef & $\overline{r x}_{t+1}$ & 0.84 & 0.64 & & & 0.30 \\
\hline Coef & $\overline{r x}_{t+1}$ & 0.68 & 0.52 & 0.62 & & 0.34 \\
\hline
\end{tabular}




\begin{tabular}{|c|c|c|c|c|c|c|}
\hline \multicolumn{7}{|c|}{ 1980:1-1989:12 } \\
\hline & $\mathrm{n}$ & $\mathrm{CP}_{\mathrm{t}}$ & $\mathrm{LN}_{\mathrm{t}}$ & $\mathrm{BW}_{\mathrm{t}}$ & $\mathrm{R}^{2}$ & Partial $\mathrm{R}^{2}$ \\
\hline $\begin{array}{l}\text { Coef } \\
\text { s.e }\end{array}$ & 2 & $\begin{array}{c}0.38 \\
(0.12)\end{array}$ & $\begin{array}{c}0.30 \\
(0.16)\end{array}$ & & 0.34 & \\
\hline Coef & & 0.27 & 0.22 & 0.33 & 0.36 & \\
\hline s.e & & $(0.10)$ & $(0.14)$ & $(0.32)$ & & \\
\hline Coef & 3 & 0.70 & 0.46 & & 0.35 & \\
\hline s.e & & $(0.23)$ & $(0.26)$ & & & \\
\hline Coef & & 0.63 & 0.41 & 0.22 & 0.36 & \\
\hline s.e & & $(0.19)$ & $(0.25)$ & $(0.53)$ & & \\
\hline Coef & 4 & 1.03 & 0.50 & & 0.36 & \\
\hline s.e & & $(0.34)$ & $(0.33)$ & & & \\
\hline Coef & & 1.02 & 0.49 & 0.05 & 0.36 & \\
\hline s.e & & $(0.28)$ & $(0.35)$ & $(0.71)$ & & \\
\hline Coef & 5 & 1.16 & 0.57 & & 0.31 & \\
\hline s.e & & $(0.44)$ & $(0.45)$ & & & \\
\hline Coef & & 1.14 & 0.56 & 0.07 & 0.30 & \\
\hline s.e & - & $(0.38)$ & $(0.44)$ & $(0.86)$ & & \\
\hline Coef & $r x_{t+1}$ & 0.91 & & & & 0.32 \\
\hline Coef & $\overline{r x}_{t+1}$ & 0.81 & 0.46 & & & 0.34 \\
\hline Coef & $\overline{r x}_{t+1}$ & 0.76 & 0.42 & 0.17 & & 0.35 \\
\hline \multicolumn{7}{|c|}{ 1990:1-1999:12 } \\
\hline & $\mathrm{n}$ & $\mathrm{CP}_{\mathrm{t}}$ & $\mathrm{LN}_{\mathrm{t}}$ & $\mathrm{BW}_{\mathrm{t}}$ & $\mathrm{R}^{2}$ & Partial $\mathrm{R}^{2}$ \\
\hline Coef & 2 & 0.51 & 0.30 & & 0.44 & \\
\hline s.e & & $(0.08)$ & $(0.17)$ & & & \\
\hline Coef & & 0.51 & 0.30 & 0.01 & 0.44 & \\
\hline s.e & & $(0.07)$ & $(0.18)$ & $(0.31)$ & & \\
\hline Coef & 3 & 1.05 & 0.36 & & 0.41 & \\
\hline s.e & & $(0.13)$ & $(0.32)$ & & & \\
\hline Coef & & 1.05 & 0.36 & 0.05 & 0.42 & \\
\hline s.e & & $(0.11)$ & $(0.32)$ & $(0.60)$ & & \\
\hline Coef & 4 & 1.62 & 0.36 & & 0.43 & \\
\hline s.e & & $(0.18)$ & $(0.45)$ & & & \\
\hline Coef & & 1.61 & 0.36 & 0.04 & 0.43 & \\
\hline s.e & & $(0.15)$ & $(0.45)$ & $(0.86)$ & & \\
\hline $\begin{array}{l}\text { Coef } \\
\text { s.e }\end{array}$ & 5 & $\begin{array}{c}2.04 \\
(0.24)\end{array}$ & $\begin{array}{c}0.18 \\
(0.55)\end{array}$ & & 0.41 & \\
\hline Coef & & 2.03 & 0.18 & 0.08 & 0.41 & \\
\hline s.e & & $(0.21)$ & $(0.55)$ & (1.10) & & \\
\hline Coef & $\overline{r x}_{t+1}$ & 1.50 & & & & 0.40 \\
\hline Coef & $\overline{r x}_{t+1}$ & 1.30 & 0.30 & & & 0.42 \\
\hline Coef & $\overline{r x}_{t+1}$ & 1.30 & 0.30 & 0.04 & & 0.42 \\
\hline
\end{tabular}

Notes: The table reports estimates from OLS regressions of excess bond returns on the lagged variables named in row 1. The dependent variable $r x_{t+1}^{(n)}$ is the excess return on the $n$-year Treasury bond. $\mathrm{CP}_{\mathrm{t}}$ is the Cochrane and Piazzesi (2005) factor that is a linear combination of five forward rates. $\mathrm{LN}_{\mathrm{t}}$ is the Ludvigson and $\mathrm{Ng}$ macro factor (2009) that is a combination of five factors estimated by the method of principal factor applied to a panel of of data with 132 individual series. $\mathrm{BW}_{\mathrm{t}}$ is the investor sentiment factor (see eqn 14) that is a linear combination of variables related to the sentiment index defined in Baker and Wurgler (2006). Hansen and Hodrick standard errors are reported in parentheses. 
Table 8. Diebold and Mariano (1995) predictive ability tests.

\begin{tabular}{cccc|ccc|ccc}
\hline \multicolumn{1}{c}{$1965: 08-1979: 12--1989: 12$} & $1975: 08-1989: 12-1999: 12$ & $1985: 08-1999: 12-2007: 12$ \\
\hline $\mathrm{n}$ & MSPE $_{\mathrm{r}}$ & MSPE $_{\mathrm{u}}$ & $\mathrm{p}$-value & MSPE $_{\mathrm{r}}$ & MSPE $_{\mathrm{u}}$ & $\mathrm{p}$-value & MSPE $_{\mathrm{r}}$ & MSPE $_{\mathrm{u}}$ & $\mathrm{p}$-value \\
\hline 2 & 4.3326 & 4.3734 & 0.7482 & 0.9905 & 1.0738 & 0.9985 & 1.3318 & 1.2649 & 0.3312 \\
\hline 3 & 15.150 & 15.669 & 0.9788 & 3.9611 & 3.9623 & 0.5092 & 4.9926 & 4.6291 & 0.2519 \\
\hline 4 & 29.296 & 30.504 & 0.9712 & 8.2478 & 7.9980 & 0.0023 & 9.2154 & 8.8175 & 0.3316 \\
\hline 5 & 48.511 & 50.180 & 0.9547 & 13.2374 & 12.868 & 0.0043 & 14.798 & 14.288 & 0.3530 \\
\hline
\end{tabular}

Notes: The table reports the MSPE for the restricted and unrestricted regression models. The restricted model corresponds to the regression model containing the $\mathrm{CP}$ and $\mathrm{LN}$ factors, and the unrestricted version also considers the BW factor. The $\mathrm{p}$-value reports the probability $\mathrm{P}(\mathrm{Z}>\mathrm{z})$ with $\mathrm{Z}$ a standard Normal random variable and $\mathrm{z}$ the value of the Diebold and Mariano test statistic defined as $z=P^{1 / 2} X / S E(X)$ with $P$ the out-of-sample period, $X$ the difference in MSPE between the restricted and unrestricted model over the out-of-sample evaluation period and $\mathrm{SE}(\mathrm{X})$ its sample standard error. Each subsample contains an in-sample period for estimating the parameters of the model and an out-of-sample period for computing the loss function of each regression specification. 
Table 9. Estimates of the investor sentiment model. GSW (2006) data.

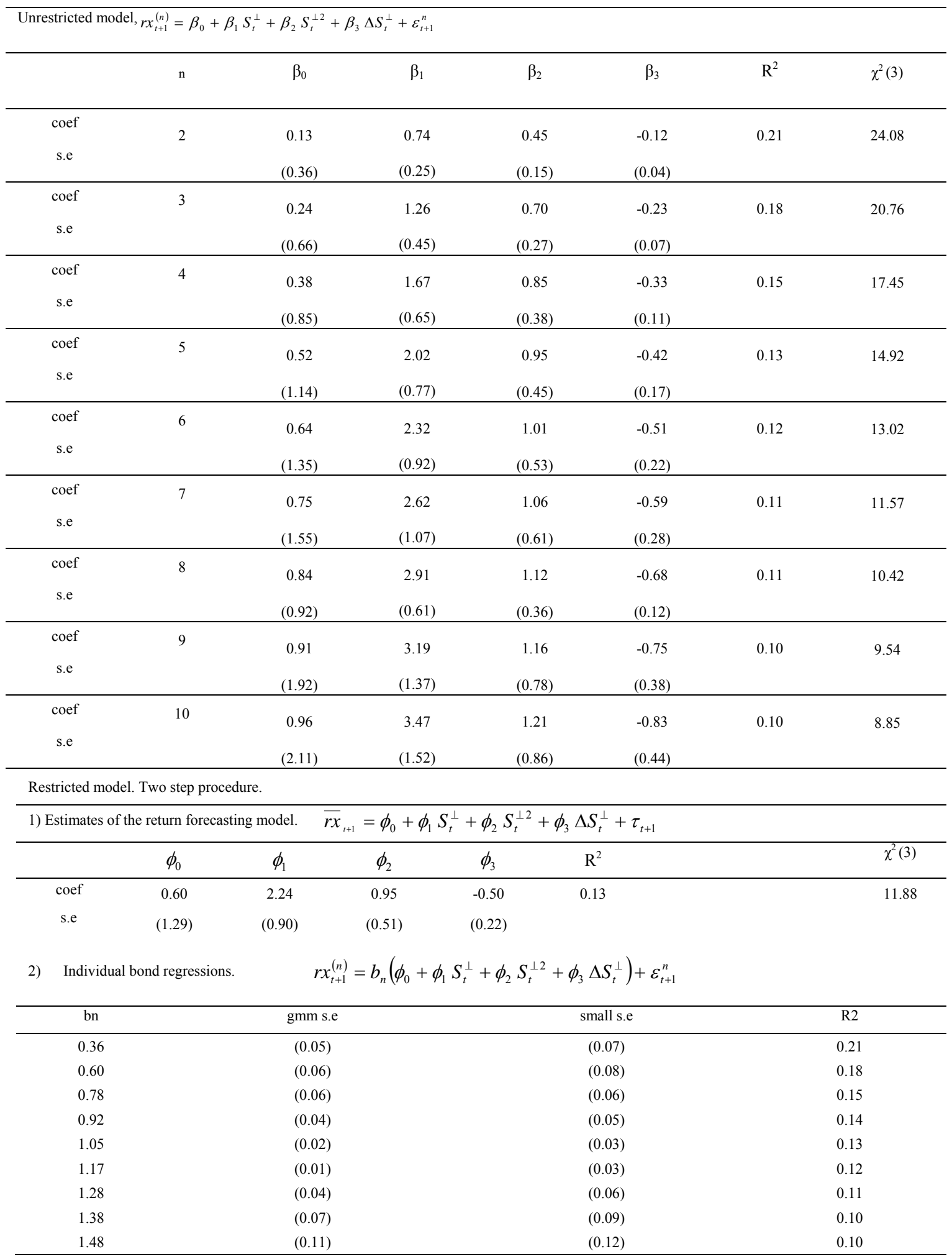

Notes: The unrestricted model reports estimates from OLS regressions of excess bond returns on the investor sentiment variables. The dependent variable $r x_{t+1}^{n}$ is the excess return on the $n$-year Treasury bond. $\mathrm{S}_{t} \perp$ is the investor sentiment variable defined in Baker and Wurgler (2006) and $\Delta \mathrm{S}_{t}^{\perp}$ is the annual change of $\mathrm{S}_{t} \perp$. Hansen and Hodrick standard errors are reported in parentheses. The restricted model reports estimates from OLS regressions of excess bond returns on the $\mathrm{BW}_{\mathrm{t}}$ factor. The sample spans the period 1972:8-2007:12 using data from Gurkaynack, Sack and Wright (2006). 
Table 10. Regressions of monthly excess bond returns on lagged factors. GSW (2006) data.

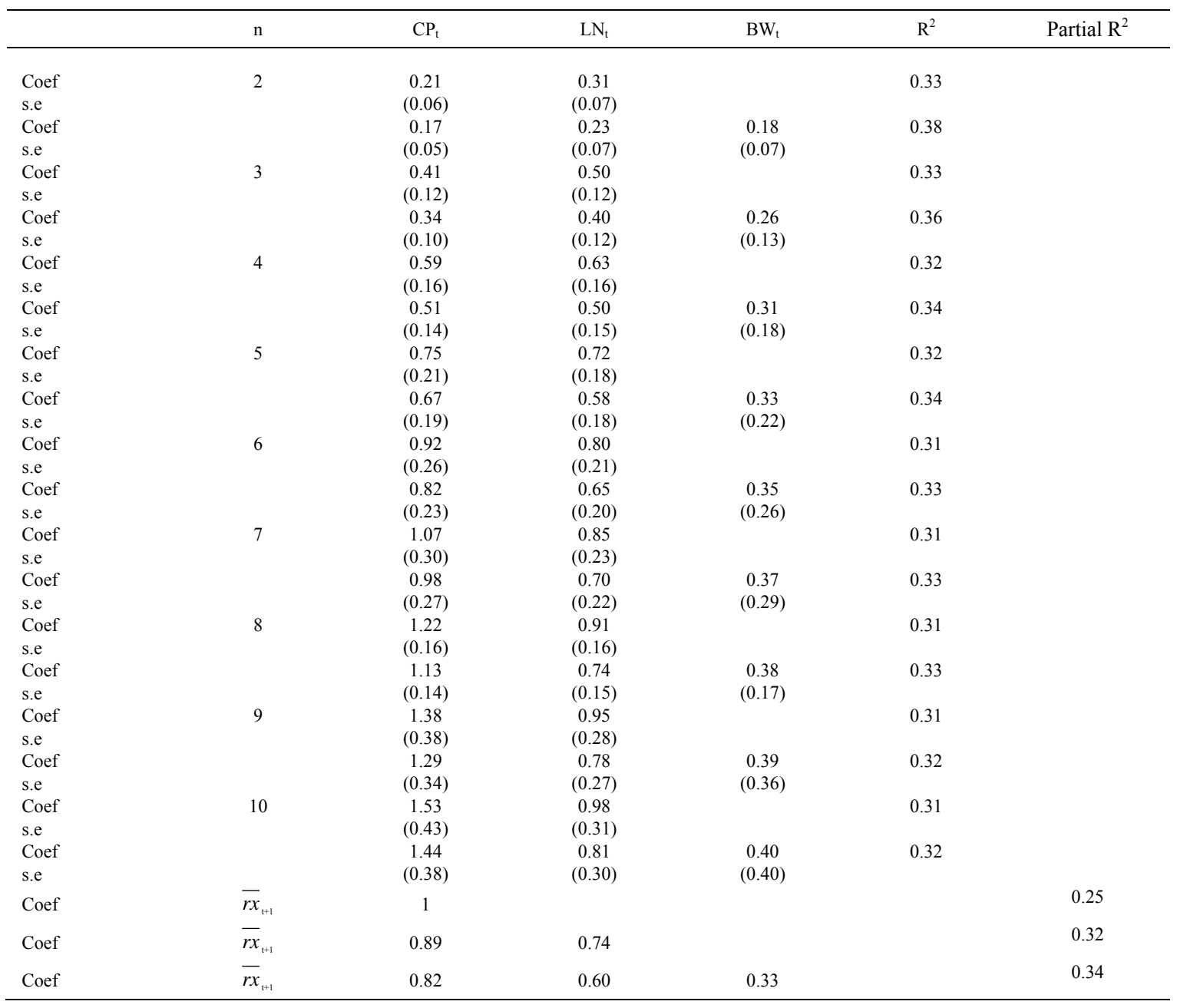

Notes: The table reports estimates from OLS regressions of excess bond returns on the lagged variables named in row 1. The dependent variable is the excess return on the n-year Treasury bond. $\mathrm{CP}_{\mathrm{t}}$ is the Cochrane and Piazzesi (2005) factor that is a linear combination of five forward rates. $\mathrm{LN}_{\mathrm{t}}$ is the Ludvigson and $\mathrm{Ng}$ macro factor (2009) that is a combination of six factors estimated by the method of principal factor applied to a panel of of data with 132 individual series. $\mathrm{BW}_{\mathrm{t}}$ is the investor sentiment factor (see eqn. 14) that is a linear combination of variables related to the sentiment index defined in Baker and Wurgler (2006). Hansen and Hodrick standard errors are reported in parentheses. The sample spans the period 1972:8-2007:12 using data from Gurkaynack, Sack and Wright (2006). 
Figure 1. The Investor Sentiment Index: January 1967 through December 2007.

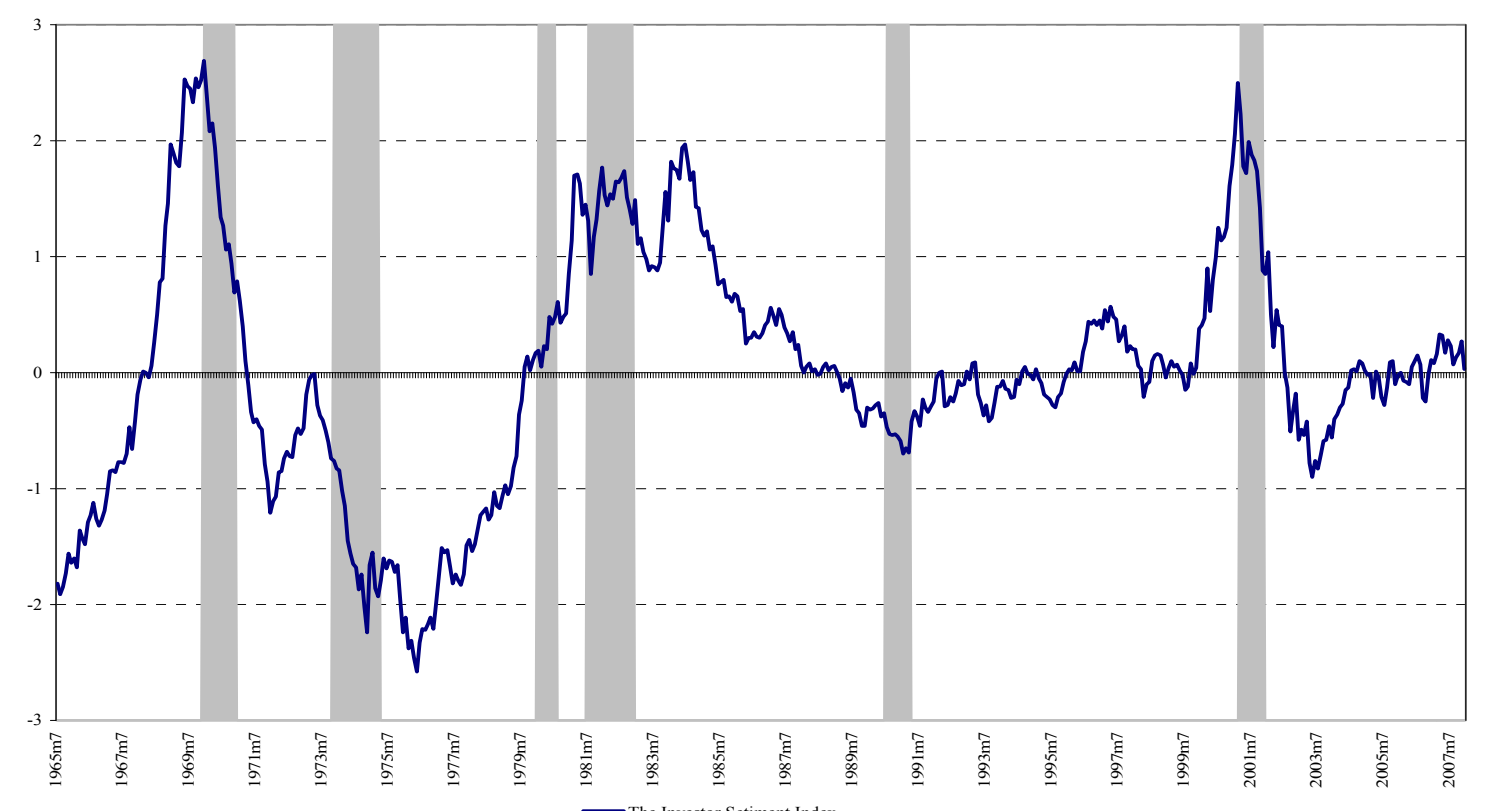

Notes: The investor sentiment index created by Baker and Wurgler (2006) and available at the Wurgler' web page (http://pages.stern.nyu.edu/ jwurgler/) is the first principal component of levels in six measures of sentiment: the closed-end fund discount, detrended log turnover, the number of IPOs, the first-day return on IPOs, the dividend premium, and the equity share in new issues, each standardized and with the effect of macroeconomic conditions removed. Shadings denote months designated as recessions by the National Bureau of Economic Research.

Figure 2. 10 year moving average correlation of Investor Sentiment Index vs. US Fed rate

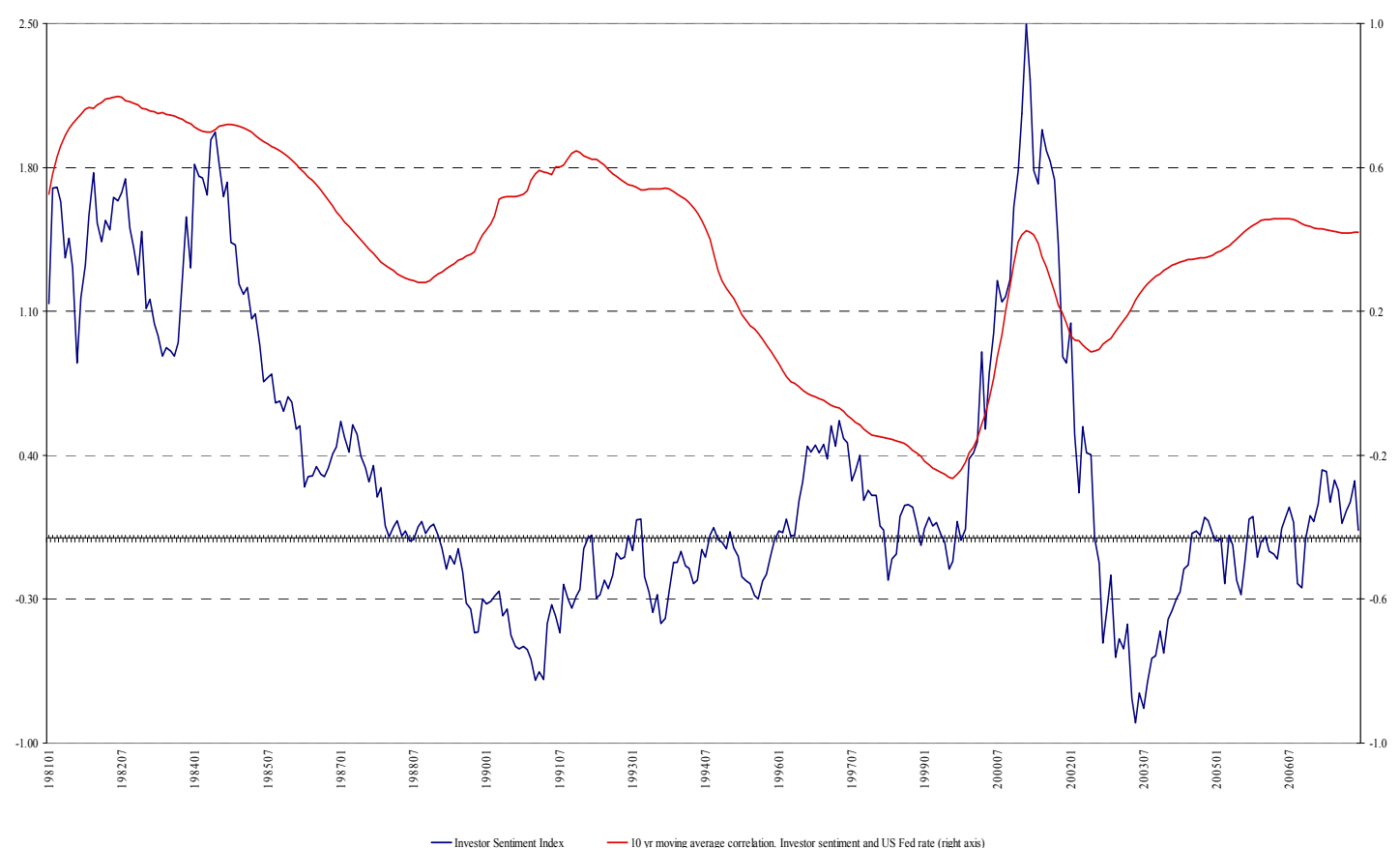

Notes: The investor sentiment index created by Baker and Wurgler (2006) and available at the Wurgler' web page (http://pages.stern.nyu.edu/ jwurgler/) is the first principal component of levels in six measures of sentiment: the closed-end fund discount, detrended log turnover, the number of IPOs, the first-day return on IPOs, the dividend premium, and the equity share in new issues, each standardized and with the effect of macroeconomic conditions removed. The period spans the period January 1971-December 2007. 
Figure 3. Regression coefficients of one year excess returns on investor sentiment variables.
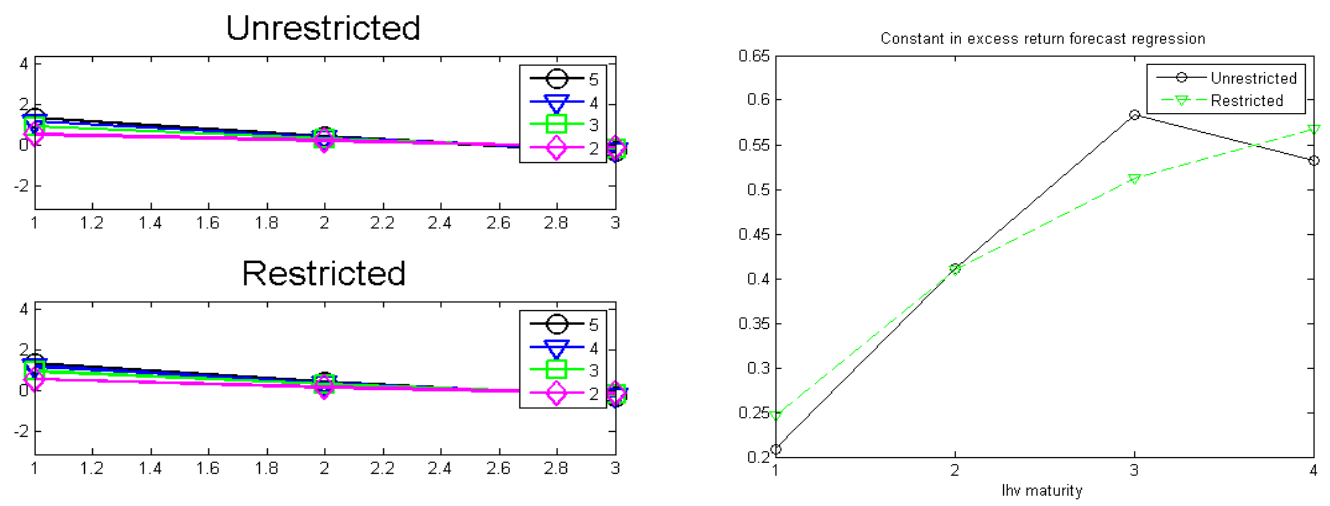

Notes: The left top panel presents estimates from the unrestricted regressions of bond excess returns, $r x_{t+1}^{(n)}$, on all the investor sentiment variables. The left bottom panel presents estimates from the restricted regressions of bond excess returns on all the investor sentiment variables. The right panel depicts the constant of the regression model of $r x_{t+1}^{(n)}$ on the investor sentiment variables for maturity $n=2,3,4,5$.

Figure 4. Dynamics of the different single-return forecasting factors.

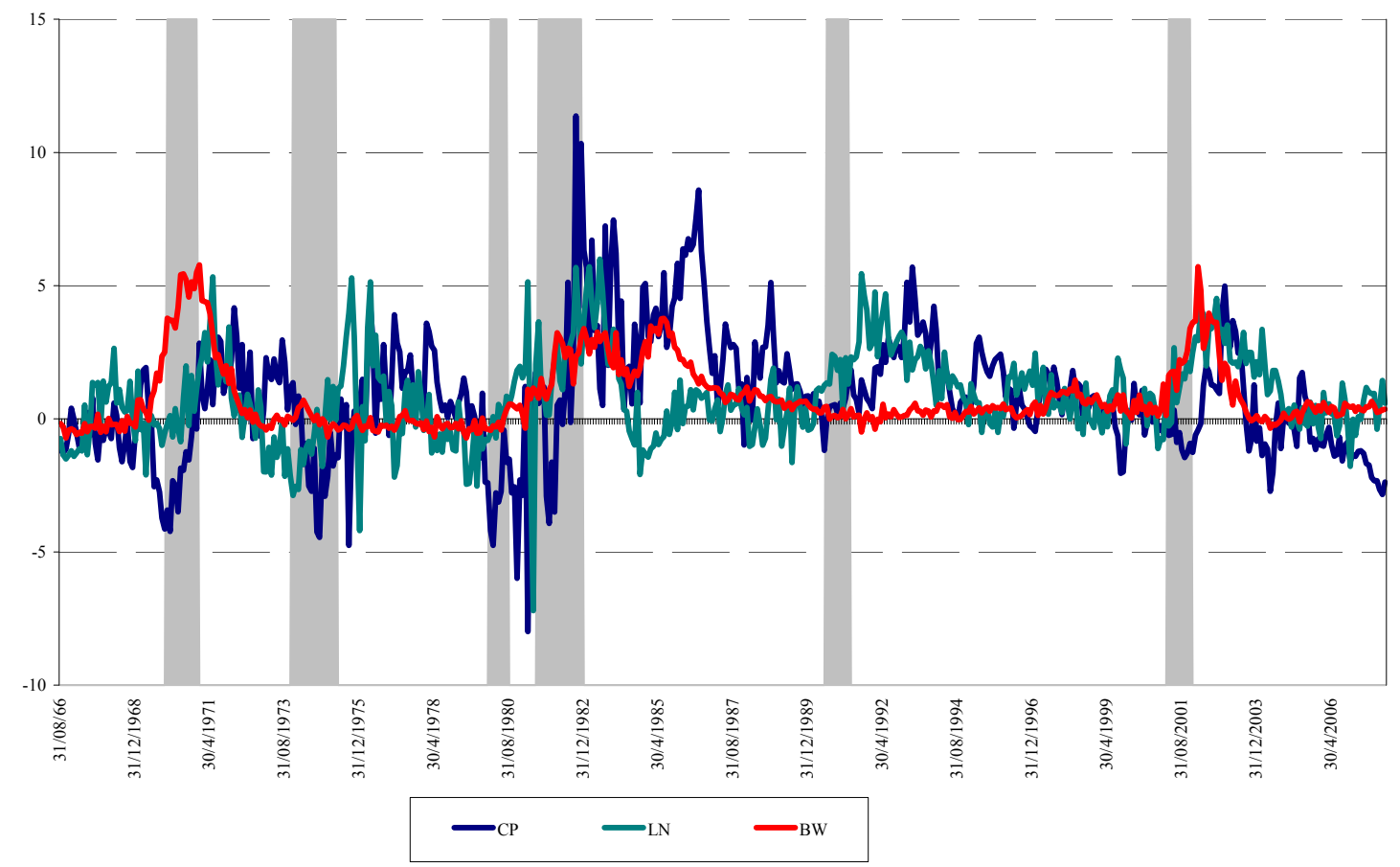

Notes: CP, LN and BW are the fitted average excess return on an equally-weighted portfolio of bonds with maturities between two and five years using interest rates (eqn. 9), macroeconomic factors (eqn. 12) and investor sentiment variables (eqn. 14) respectively. Shadings denote months designated as recessions by the National Bureau of Economic Research. 
Figure 5. Cumulative profits from trading rules. Out-of-sample performance. $\mathbf{n}=2$.
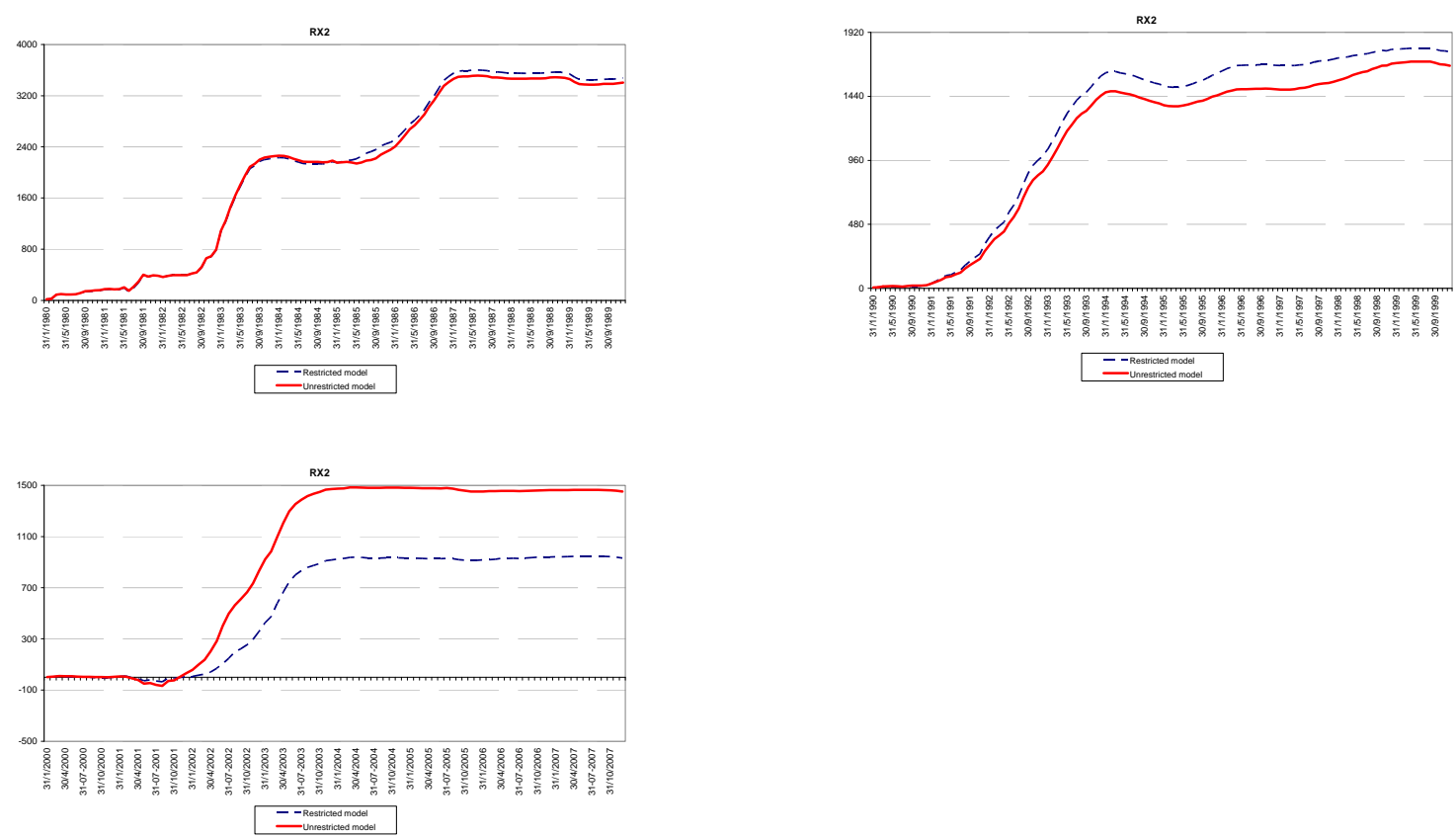

Figure 6. Cumulative profits from trading rules. Out-of-sample performance. $n=3$.
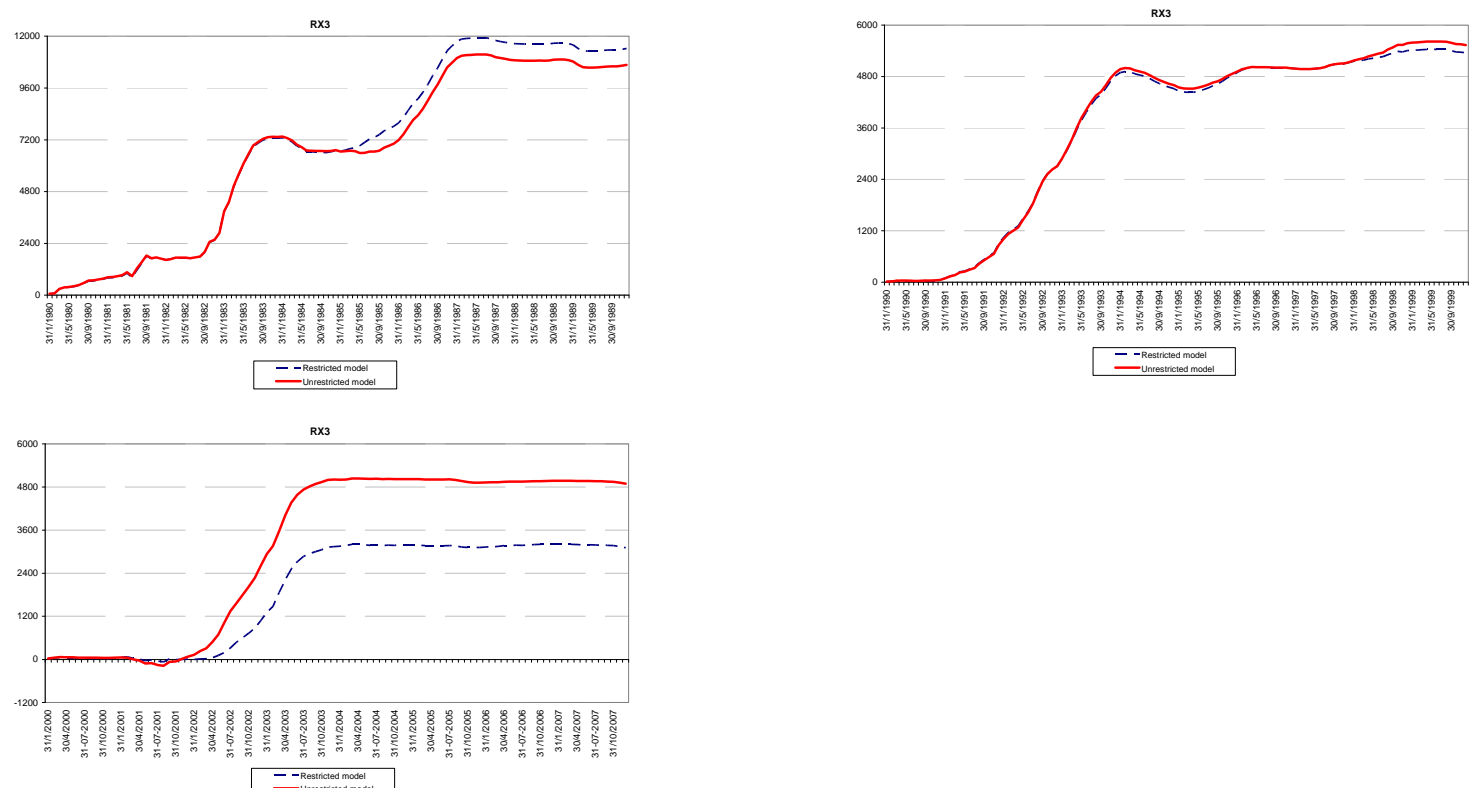

Notes: Each line plots the cumulative value of $\mathrm{rx}_{t+1}^{(n)} \times \mathrm{E}_{\mathrm{t}}\left(\mathrm{rx}_{t+1}^{(n)}\right)$ for $\mathrm{n}=2,3 . \mathrm{E}_{\mathrm{t}}\left(\mathrm{rx}_{t+1}^{(n)}\right)$ are out-of-sample forecasts estimated by OLS in rolling regressions of 120 months. The initial estimation period spans the period August 1965December 1979 and January 1980-December 1989 as the out-of-sample for model evaluation. The second in-sample estimation period covers August 1975-December 1989 and the out-of-sample covers January 1990-December 1999. The last period is defined by the interval August 1985-December 1999 and considers the remaining eight years of data for out-of-sample evaluation. The unrestricted model line uses the forecast form the unrestricted model that includes the $\mathrm{CP}_{\mathrm{t}}$ factor, the $\mathrm{LN}_{\mathrm{t}}$ factor and $\mathrm{BW}_{\mathrm{t}}$ factor, that considers investor sentiment variables. The restricted model line uses the forecast from the restricted model that excludes the investor sentiment variables. 
Figure 7. Cumulative profits from trading rules. Out-of-sample performance. $n=4$.
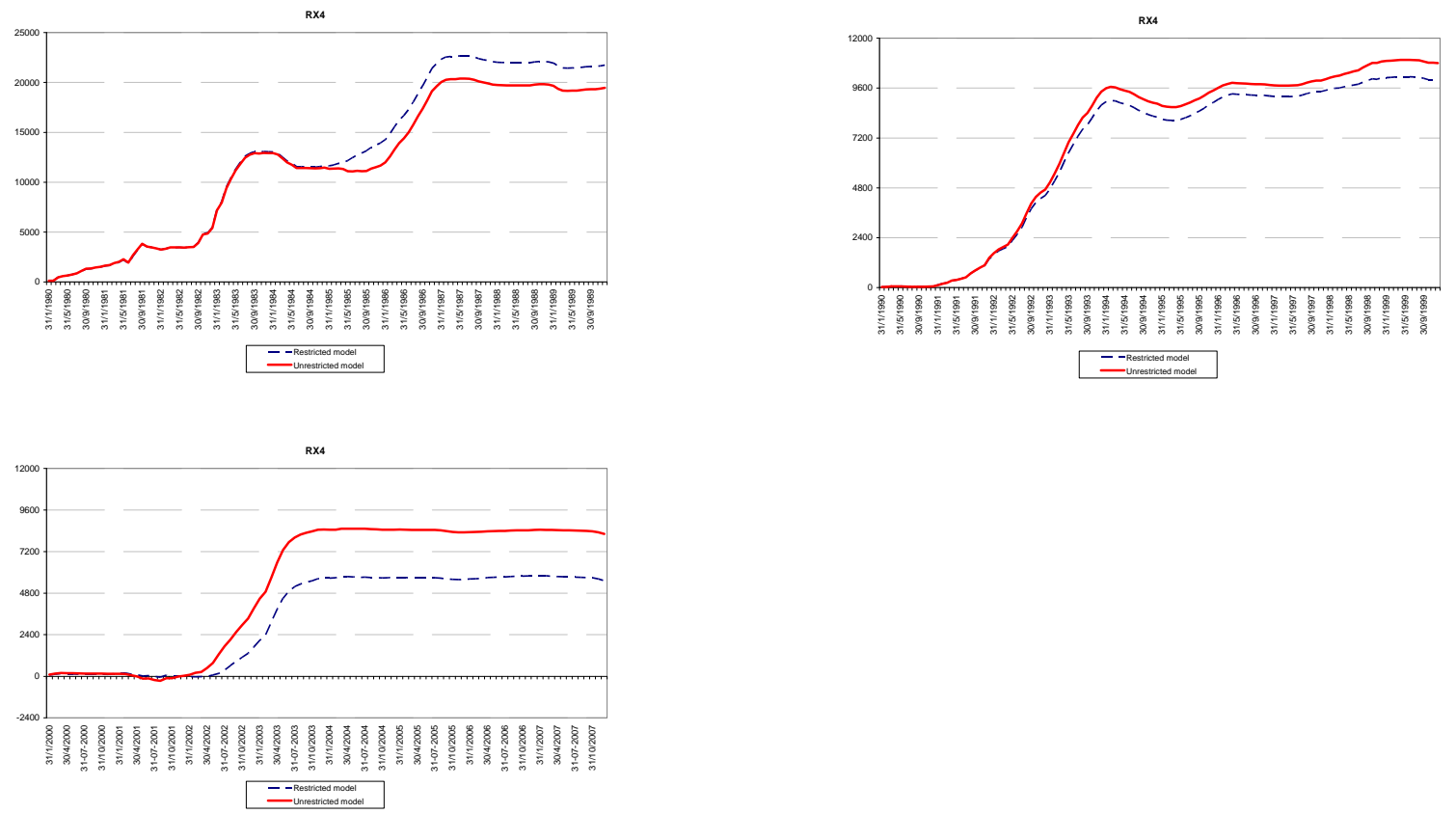

Figure 8. Cumulative profits from trading rules. Out-of-sample performance. $n=5$.
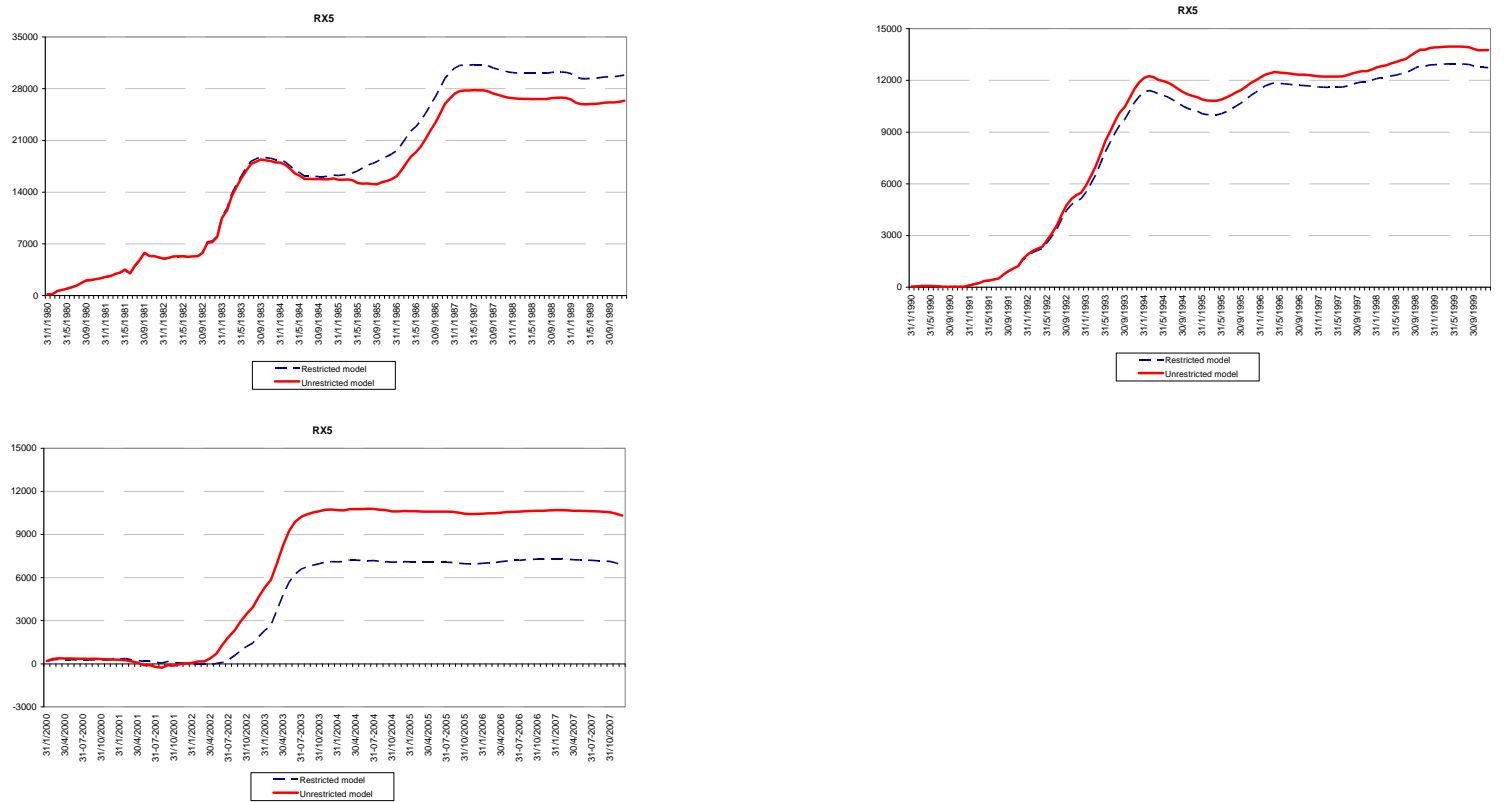

Notes: Each line plots the cumulative value of $\mathrm{rx}_{t+1}^{(n)} \times \mathrm{E}_{\mathrm{t}}\left(\mathrm{rx}_{t+1}^{(n)}\right)$ for $\mathrm{n}=4,5 . \mathrm{E}_{\mathrm{t}}\left(\mathrm{rx}_{t+1}^{(n)}\right)$ are out-of-sample forecasts estimated by OLS in rolling regressions of 120 months. The initial estimation period spans the period August 1965December 1979 and January 1980-December 1989 as the out-of-sample for model evaluation. The second in-sample estimation period covers August 1975-December 1989 and the out-of-sample covers January 1990-December 1999. The last period is defined by the interval August 1985-December 1999 and considers the remaining eight years of data for out-of-sample evaluation. The unrestricted model line uses the forecast form the unrestricted model that includes the $\mathrm{CP}_{\mathrm{t}}$ factor, the $\mathrm{LN}_{\mathrm{t}}$ factor and $\mathrm{BW}_{\mathrm{t}}$ factor, that considers investor sentiment variables. The restricted model line uses the forecast from the restricted model that excludes the investor sentiment variable 